\title{
Small Molecule Inhibitors Targeting Chikungunya Virus
}

\author{
Nicole Haese, John Powers and Daniel N. Streblow
}

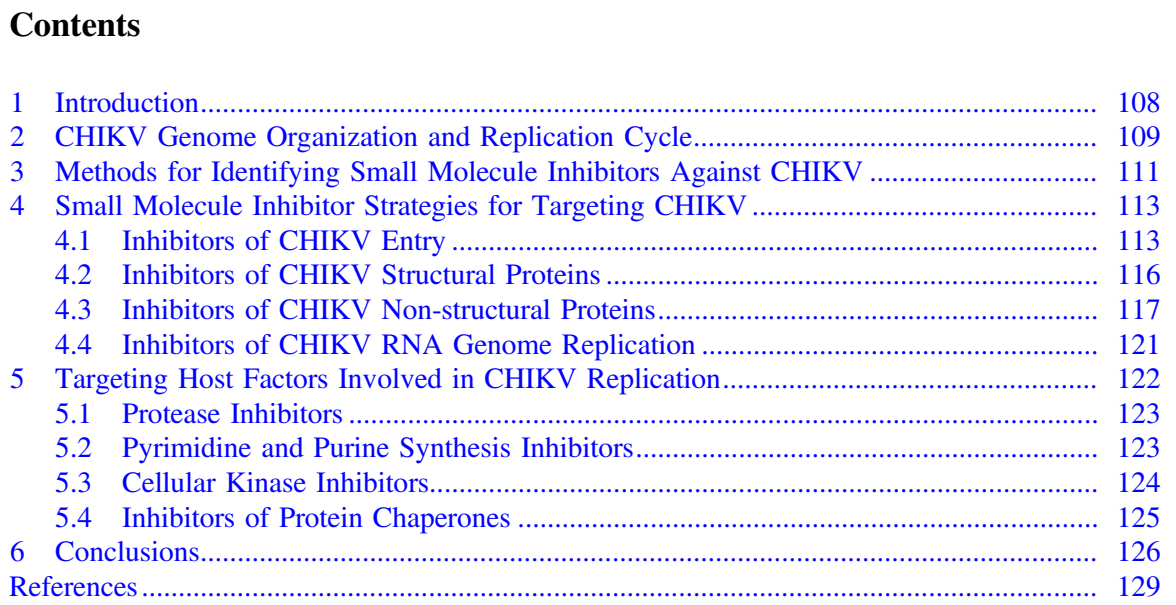

\begin{abstract}
Chikungunya virus (CHIKV) infection in humans is rarely fatal but is often associated with chronic joint and muscle pain. Chronic CHIKV disease is highly debilitating and is associated with viral persistence. To date, there are no approved vaccines or therapeutics to prevent or treat $\mathrm{CHIKV}$ infections once they are established. Current palliative treatments aim to reduce joint inflammation and pain associated with acute and chronic CHIKV disease. Development of novel
\end{abstract}

\footnotetext{
N. Haese · J. Powers · D. N. Streblow $(\bowtie)$

Vaccine and Gene, Therapy Institute and Oregon National Primate Research Center, Oregon Health \& Science University, 505 NW 185th Avenue, 97006 Beaverton, OR, USA

e-mail: streblow@ohsu.edu

Current Topics in Microbiology and Immunology (2022) 435: 107-139

https://doi.org/10.1007/82_2020_195

(C) Springer Nature Switzerland AG 2020

Published online: 24 January 2019
} 
therapeutics that reduces viral loads should positively impact virus inflammatory disease and improve patient outcomes following CHIKV infection. Therapies that target multiple aspects of CHIKV replication cycle should be developed since the virus is capable of rapidly mutating around any single therapeutic. This review summarizes the current status of small molecule inhibitor development against CHIKV.

\section{Introduction}

Chikungunya virus (CHIKV) is an alphavirus of the Togaviridae family transmitted to humans by Aedes mosquitoes. Since CHIKV was first isolated, the virus has spread causing multiple endemic and large epidemic outbreaks. Virus sequencing has identified the emergence of four different virus lineages driven, in part, by adaptation of the virus to A. albopictus mosquitoes during the 2000s outbreak. This adaptation allowed virus transmission into more temperate climates (Schuffenecker et al. 2006; Tsetsarkin et al. 2007). Interest in CHIKV has been driven by the recent re-emergence of the virus. CHIKV emerged on a global level starting on the coast of Kenya in 2004, in a wave that continued to spread across the islands of the Indian Oceans. This spread continued to Asia before arriving in the Caribbean region in 2013, Brazil in 2014 and then the rest of the American continents (Charrel et al. 2007; Weaver and Lecuit 2015; Yang et al. 2017). During this time, CHIKV outbreaks were also reported in Italy and France due to the emergence of the ability to use A. albopictus mosquitoes as a transmission vector (Cassadou et al. 2014; Rezza et al. 2007; Venturi et al. 2017). While the most recent reported outbreak of CHIKV was in Mombasa, Kenya in February 2018 (WHO Web site), this cycle of emergence and global spread is likely to repeat as antiviral immunity wanes at the population level.

Infection with CHIKV causes a febrile illness that is highly associated with severe joint/muscle pain and is often accompanied by a rash. For some individuals, the infection is self-limiting and symptoms resolve within a few weeks following infection. However, about $40-80 \%$ of those infected will continue to experience chronic joint and muscle pain that can last for months to years after CHIKV infection (Borgherini et al. 2008; Gerardin et al. 2008). Viral RNA can be detected long term in these patients, but the precise mechanisms that contribute to the development of chronic CHIKV disease are still unclear (Chopra et al. 2012; Simon et al. 2015; Sissoko et al. 2009). Atypical complications of CHIKV infection may occur in the elderly and in individuals with comorbidities, such as encephalitis (Lebrun et al. 2009). Fetal CHIKV infections during pregnancy are rare, but perinatal infection of newborns occurs during the intrapartum period, resulting in a high mortality rate and those surviving may suffer severe, lifelong neurological outcomes (Bandeira et al. 2016; Gopakumar et al. 2012; Lyra et al. 2016).

Currently, there is no licensed virus-specific treatment to prevent or treat CHIKV infection and disease. Extensive time and effort have gone into the development of 
multiple anti-CHIKV treatment platforms including vaccines, gene and immunotherapeutic strategies, as well as small molecule inhibitors. Herein, we focus on recent advances in the development of small molecule inhibitors directed against $\mathrm{CHIKV}$ replication as treatments for viral infection and disease.

\section{CHIKV Genome Organization and Replication Cycle}

CHIKV contains a single-stranded, positive-sense linear genome that is approximately $11.8 \mathrm{~kb}$ in length (Fig. 1) (Solignat et al. 2009). The genome contains two open reading frames (ORFs), and unique polyproteins are generated from two individual RNA species (Simmons and Strauss 1972; Strauss et al. 1984). The non-structural proteins (nsP1-4) are created from full-length, genomic mRNA, whereas the structural polyprotein containing capsid, E3, E2, 6K, and E1 are synthesized from a subgenomic mRNA (sgmRNA) species. Both genomic and sgmRNAs are flanked by a 5' 7-methylguanosine cap and a $3^{\prime}$ polyadenylated tail (Dubin and Stollar 1975; Dubin et al. 1977). There are three untranslated regions (UTRs) within the genome; individual UTRs present at the $5^{\prime}$ and $3^{\prime}$ ends, and the third UTR is located between the ORFs, which contains the promoter sequence present on the sgmRNA that is required for translation of the structural polyprotein.

The CHIKV replication cycle is shown in Fig. 2. The Chikungunya virion contains 80 trimeric spikes of E1 and E2 glycoprotein heterodimers on the surface (Voss et al. 2010). E2 facilitates attachment to host cells followed by internalization through clathrin-mediated endocytosis (CME). Within the early endosomes, the E1 protein facilitates $\mathrm{pH}$-dependent fusion of the viral envelope with the endosomal membrane (van Duijl-Richter et al. 2015). This process is followed by disassembly of the virus nucleocapsid and release of the viral genome into the cytosol. The CHIKV nsPs are synthesized by the host cell translation machinery creating the precursor polyproteins P123 and P1234. The majority of the translation products are

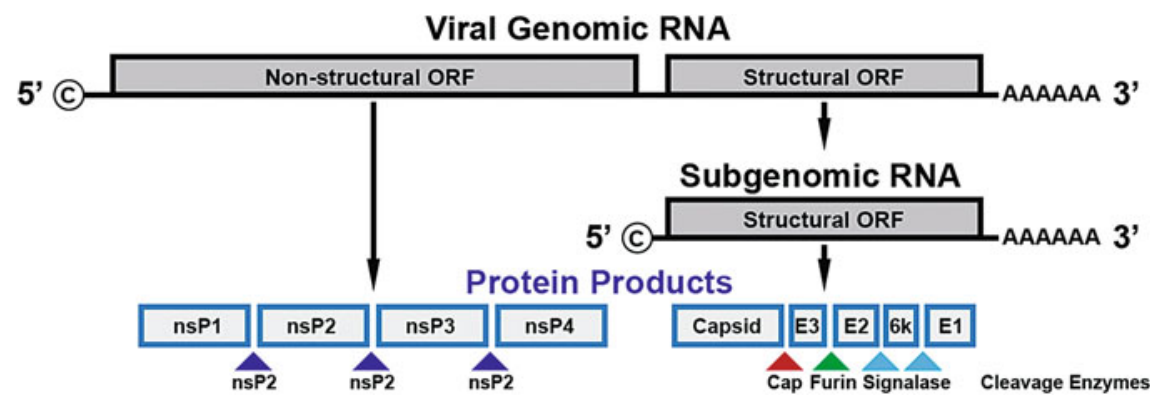

Fig. 1 Schematic representation of the Chikungunya virus genome. The CHIKV genomic and subgenomic RNAs are depicted. Following translation, the two polyproteins are cleaved by viralor host-specific proteases to release the mature forms of the viral proteins 


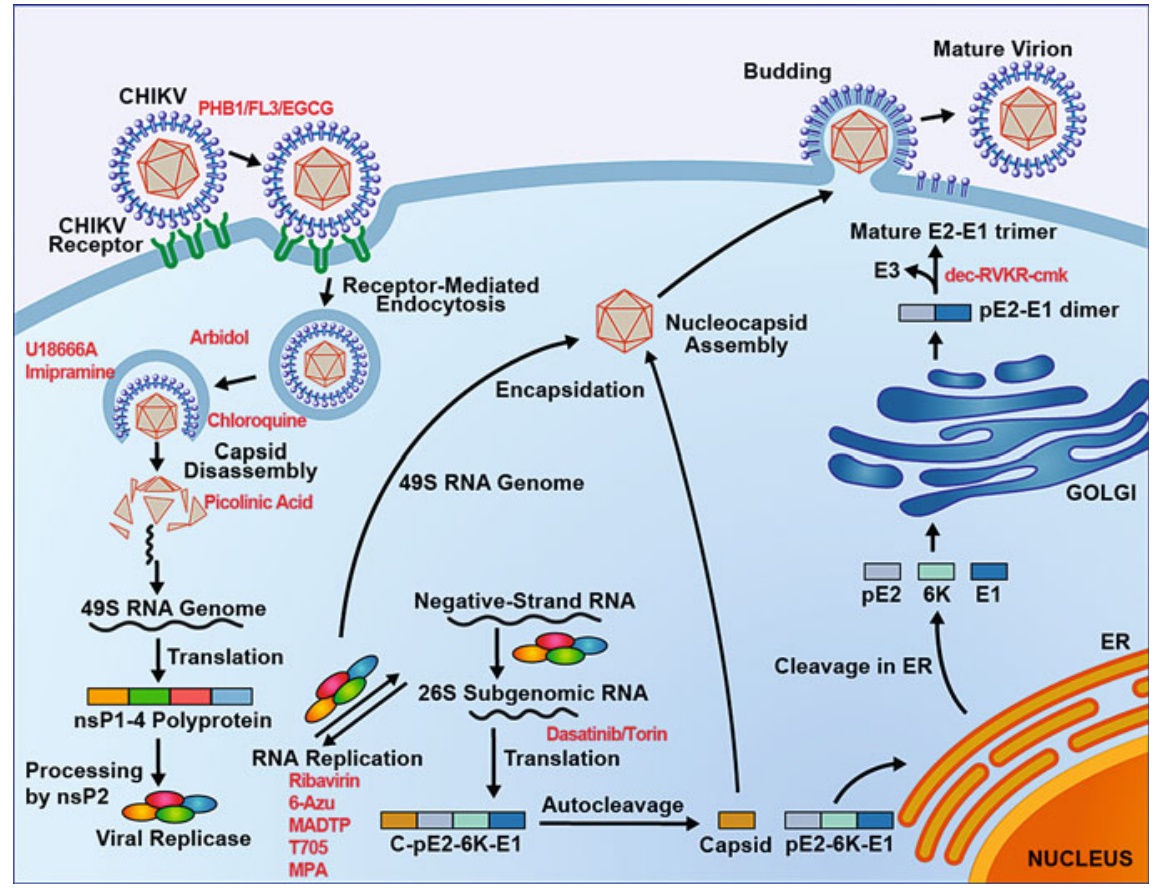

Fig. 2 Chikungunya virus replication cycle. CHIKV enters via receptor-mediated endocytosis following the binding of the envelope protein to cellular receptors (i.e., Mxra8). Low pH triggers virus particle release from the endosome. Within the cytoplasm, the virus capsid is disassembled, which allows translation of the nonstructural ORF from the viral genomic RNA. Processed nonstructural proteins form a replication complex that synthesizes both the negative strand genomic length RNA that is used as a template for the production of genomic and subgenomic RNA species. Translation of the subgenomic RNA produces the structural proteins that are processed into their mature forms required for encapsidation of the genomic RNA strand and nucleocapsid assembly. Viral envelope proteins are processed and modified in the endoplasmic reticulum and Golgi apparatus. At the plasma membrane, the glycoproteins are loaded onto viral nucleocapsids during envelopment and release at the plasma membrane. A subset of known small molecule antivirals are depicted in red lettering at their putative site of effect

P123 with P1234 only being expressed following read-through of the opal stop codon at the end of nsP3 (Strauss and Strauss 1994). Following translation, P1234 is cleaved in cis by the viral protease, nsP2, into $\mathrm{P} 123+\mathrm{nsP} 4$. These early replication complexes (RCs) formed by $\mathrm{P} 123+\mathrm{nsP} 4$ are responsible for synthesizing the negative strand genomic RNA using the positive strand as a template (Barton et al. 1991; de Groot et al. 1990; Shirako and Strauss 1994). Eventually, the P123+nsP4 RCs accumulate to a concentration threshold leading to further processing of P123. At this point, $\mathrm{nsP} 1$ is cleaved in trans forming a complex made up of nsP1+P23+nsP4 that for a short time, is capable of both negative and positive strand synthesis. Subgenomic viral RNA synthesis (Jose et al. 2009; van der Heijden and Bol 2002; Vasiljeva et al. 2003) occurs following cleavage of the P2/3 intermediate resulting in 
fully processed nsPs, forming stable late RCs capable of synthesizing both the full-length positive-sense genomic RNA and the sgmRNA (Kim et al. 2004). CHIKV replication induces the formation of host cell membrane invaginations called spherules. Spherules are connected to the cytoplasm by a narrow neck wherein early RCs are thought to localize with newly synthesized negative strand RNA. Double-stranded RNA intermediates are located in the interior of the spherule where they are protected from degradation and detection by innate immune sensors (Frolova et al. 2010; Utt et al. 2016). As the infection progresses a portion of the spherules will become internalized to form a virus-induced type 1 cytopathic vacuole (CPV) near the endoplasmic reticulum. The formation of CPVs is triggered by activation of the PI3K-AKT-mTOR pathway and is made up of membranes from both the endosome and lysosome (Spuul et al. 2010; Thaa et al. 2015).

The viral sgmRNA is translated into the structural polyprotein (capsid-E3-E26k-E1). Once formed the capsid protein undergoes immediate autocleavage, while the other proteins are still in the process of translation (Thomas et al. 2010). The cleaved capsid binds newly synthesized genomic viral RNA and facilitates the formation of the nucleocapsid core. The remaining structural protein polypeptide is cleaved by host proteases into pE2 (E3-E2), 6K, and E1. E1 and pE2 form non-covalent heterodimers that travel through the Golgi secretory pathway where they are post-translationally modified. Within the Golgi, the host enzyme furin cleaves pE2 into mature viral E2 and E3 (Ozden et al. 2008). The processed glycoproteins are transported to the plasma membrane where they are inserted into the host cell plasma membrane. At the same time, nucleocapsid cores containing infectious viral RNA genomes are recruited to the host cell plasma membrane for envelopment as the particles bud from the cell, thus completing the replication cycle (Garoff et al. 2004; Jose et al. 2012; Strauss and Strauss 1994).

\section{Methods for Identifying Small Molecule Inhibitors Against CHIKV}

The first step in many workflows for the identification of small molecule antivirals is the development and validation of a high-throughput screening (HTS) platform. A variety of CHIKV antiviral screening methods have been developed such as those based on a reduction in cellular cytopathic effect (CPE), changes in phenotype, reduction in replicon/minigenome readouts, as well as in silico virtual screening that requires solved viral protein structures.

Most conventional antiviral HTS campaigns utilize cell-based screening with readouts to measure $\mathrm{CPE}$. Similar to other viruses, CHIKV infection causes robust $\mathrm{CPE}$ that can be easily measured as an increase in cell survival for those compounds demonstrating antiviral activity. Since some compounds in libraries can exhibit cytostatic and/or cytotoxicity, CPE-reduction-based antiviral screens provide two simultaneous readouts by identifying compounds with antiviral activity and those 
with low inherent cytotoxicity. Several parameters dictate the overall effectiveness and reproducibility of CPE-based HTS assays including cell type and passage number, virus strain, multiplicity of infection, and time point of development as well as the specific readout. Modifying these culture and assay conditions allows for optimal virus growth and identifiable CPE. In CHIKV CPE assays, cell types such as Vero, A. albopictus clone (C6/36), telomerized human fibroblasts, and Baby Hamster Kidney fibroblasts (BHK-21) cells have been successfully utilized to identify antiviral compounds (Bhat et al. 2019). Cell viability assay readouts previously used for CHIKV HTS include measuring cellular dehydrogenase activity using the colorimetric dyes MTT, MTS, or XTT; mitochondrial membrane potential using fluorescent mitochondrial tracker dyes; intracellular esterase cleavage fluorescent dyes; ATP-based luciferase reagents; and those assays that measure oxygen consumption or glycolysis. While these assays indirectly measure viral infection through cell viability, direct detection of viral protein production using viral-specific antibodies or tagged viruses allows one to directly assess viral replication. Replicon-based screens that incorporate quantifiable reporters have also been very useful for testing under reduced biosafety level conditions, although modifications to the viral genome typically need to be introduced to reduce replicon cytotoxicity (Pohjala et al. 2011; Tamm et al. 2008; Frolov et al. 1999; Dryga et al. 1997). While not always straightforward for HTS development and implementation, quantification of virus production as plaque reduction can be accomplished by staining of infected cells or through quantification of produced infectious virus in the supernatants of infected cells. Since they typically require more involved techniques, these types of assays are often used to validate hits and determine $\mathrm{EC}_{50}$ values.

Other phenotypic/molecular target-based screens have been designed to measure compound effects on functions of CHIKV proteins, molecular pathways, or disease-related outcomes. These types of approaches generally start with target identification, which is based on knowledge of a known protein or pathway function, and requires the ability to design assays around the desired targets. A well-described phenotypic screen for CHIKV is based on transcriptional shutoff induced by CHIKV nsP2. In this screen, CHIKV nsP2-induced host transcriptional shutoff is connected to various luciferase-based reporter gene assays, including a trans-reporter system that employs a Gal4 DNA-binding domain fused to Fos transcription factor (Bhat et al. 2019). This has been adapted to the HTS platform and used to identify many compounds that block nsP2 mediated host shutoff (Lucas-Hourani et al. 2013b).

A rapidly growing area in antiviral development is the development of in silico virtual screens. These types of screens are knowledge-driven approaches that combine structural information about a viral or host protein of interest for target-based screens. In silico computer-based screening of bioactive ligands ranks molecules based on their likelihood of having affinity for a certain target through a multistep process of virtual docking, scoring, validation, and simulation steps (Ekins et al. 2007a, b). Compounds identified by this type of screening method can be further optimized in silico using computer-based structural models through an understanding of the compound's structure-activity relationship (Bhat et al. 2019). 
Any compound hits that come out of this type of screen should be further validated by empirical methods. Co-crystallization, differential scanning fluorimetry, and isothermal titration calorimetry are just a few. Most of these techniques require highly purified proteins. Because high-resolution structures of many CHIKV nsPs and glycoproteins are solved, they are ideal targets for the development of virtual screens and computer-aided design. Further into this chapter, we present examples of compounds identified through in silico screening methods and the methods used to validate their in vivo efficacy.

\section{Small Molecule Inhibitor Strategies for Targeting CHIKV}

\subsection{Inhibitors of CHIKV Entry}

Attachment of CHIKV particles to a host cell involves the binding of the viral E2 glycoprotein with a host cell receptor protein. CHIKV E2 has two surface-exposed domains (known as domains A and B) that are capable of binding to cells (Cho et al. 2008; Voss et al. 2010). Multiple factors are thought to be involved in CHIKV attachment including numerous proposed entry receptors including prohibitin-1, TIM-1, glycosaminoglycans, and others; thus far most of these proposed receptors act mainly as attachment factors to capture virus and facilitate entry (Hoornweg et al. 2016; Moller-Tank et al. 2013; Silva et al. 2014; van Duijl-Richter et al. 2015; Wintachai et al. 2012). Mapping studies suggest E2 domain A contains a charged heparin sulfate-binding groove that may overlap with other cellular attachment protein-binding sites (Sahoo and Chowdary 2019). Most recently, a genome-wide CRISPR-Cas9-based host gene deletion screen identified the cell adhesion molecule Mxra8 as an entry mediator for CHIKV and other alphaviruses (Zhang et al. 2018). Mxra8 binds a surface-exposed region across the A and B domains of E2, which are also speculated attachment sites (Zhang et al. 2018). Studies with Mxra8 and other potential CHIKV entry receptors presented similar conclusions that no single receptor/factor is critical for CHIKV attachment/entry, and therefore, it is a combination of host factors that likely contribute to cell attachment and entry (Moller-Tank et al. 2013; Silva et al. 2014; van Duijl-Richter et al. 2015; Wintachai et al. 2012; Zhang et al. 2018). This makes inhibition of viral entry difficult because blocking one factor of CHIKV entry will likely not be adequate to inhibit CHIKV replication. One place to start is the development of small molecule screens that target the Mxra8-binding region of E2 and the interaction sites of other putative CHIKV attachment/entry components. Treatment of mice with either an anti-Mxra8 antibody or a Mxra8-Fc fusion protein reduced CHIKV infection and associated foot swelling, suggesting that Mxra8-specific small molecule inhibitors may be an effective strategy to inhibit CHIKV infection. This strategy has yet to be successfully exploited against CHIKV, and the combination of multiple entry process inhibitors is one way to inhibit CHIKV infection during the early stages. 
After attachment, CHIKV is internalized largely through clathrin-mediated endocytosis (CME), although clathrin-independent entry has also been reported (Ooi et al. 2013; Bernard et al. 2010; van Duijl-Richter et al. 2015). Although micropinocytosis has been identified as a major route of entry in muscle cells, which was inhibited by 5-( $N$-ethyl- $N$-isopropyl)amiloride (EIPA) (Lee et al. 2019). Inside the early acidic endosome, the low $\mathrm{pH}$ environment triggers CHIKV E1-mediated fusion of the viral envelope and endosomal membranes in a process that requires the presence of cholesterol (van Duijl-Richter et al. 2015). Membrane fusion is followed by virus disassembly and release of the nucleocapsid, uncoating, and release of the viral genome into the cytosol. Interfering with the formation of clathrin-coated pits and membrane fusion by adjusting endosome $\mathrm{pH}$ are successful strategies to inhibit CHIKV entry.

In 2012, the first CHIKV receptor prohibitin-1 (PHB1) was described, acting as a CHIKV-binding factor in human microglia cells (Wintachai et al. 2012). In addition, a class of naturally occurring plant compounds, flavaglines (FL), as well as their synthetic analogs (FL3 and FL23), and sulfonyl amides, are able to interact with PHB1 (Chang et al. 2011; Ribeiro Morais et al. 2011), representing a class of potential CHIKV inhibitors. Replication of CHIKV in HEK293 cells was maximally inhibited when cells were treated with the synthetic flavaglines FL3 and FL23 prior to CHIKV infection (Wintachai et al. 2015). However, little inhibitor activity was detected following a post-entry treatment regimen, suggesting FL3 and FL23 are capable of only inhibiting virus entry. In PHB-CHIKV E2 co-localization, there was a significant reduction in binding interactions between PHB1 and CHIKV E2 glycoprotein in the presence of FL3 or FL23, with reduction also occurring in the presence of the sulfonyl amide $1 \mathrm{~m}$ inhibitor. Approximately fifty percent of treated cells still displayed signs of infection, again indicating the role of additional coreceptors or CHIKV entry mechanisms.

Epigallocatechin-3-gallate (EGCG) is another naturally occurring compound that inhibited CHIKV infection (Weber et al. 2015). A major component of green tea, EGCG has displayed antiviral abilities through an interaction with viral surface proteins that inhibits cellular attachment (Kaihatsu et al. 2018). While concurrent administration of EGCG with infectious CHIKV was able to reduce the rate of infection, this was not observed when EGCG was added following infection with CHIKV (Lu et al. 2017). This finding supports the proposed mechanism that EGCG functions as an antiviral through the inhibition of entry rather than inhibiting viral replication (Weber et al. 2015). This inhibition has been documented to affect the infectivity of both sialic acid and heparan-sulfate-binding viruses, inhibiting attachment of adenovirus, vesicular stomatitis virus, and vaccinia virus among others (Colpitts and Schang 2014).

Chloroquine is another broadly acting antiviral compound with efficacy against CHIKV. Initially developed as an antimalarial drug, chloroquine acts as a broad-spectrum antiviral through disruption of endosomal entry of viruses and inhibiting replication. Along with these activities, accumulation of chloroquine in lymphocytes and macrophages disrupts the secretion of proinflammatory molecules, such as tumor necrosis factor $\alpha(\mathrm{TNF} \alpha)$ and the receptor for $\mathrm{TNF} \alpha$ 
(Savarino et al. 2003). When tested for CHIKV inhibition, chloroquine was found to act in a time- and dose-specific manner. Pre-treatment inhibited viral binding to cells, likely by altering cell-virus interactions. Chloroquine was previously identified to alter the terminal glycosylation of angiotensin I converting enzyme 2 (ACE2), a receptor for severe acute respiratory syndrome coronavirus (SARS-CoV). It is likely that chloroquine may act in a similar function to disrupt cellular receptors important for CHIKV infection (Khan et al. 2010). When chloroquine was provided concurrently with infectious CHIKV, or up to 1-hour post-infection, CHIKV infection was reduced, likely through the $\mathrm{pH}$ modulating effects of chloroquine on endosomes. This alteration in endosomal $\mathrm{pH}$ presumably inhibited virus-endosome interactions required for conformational changes in unpackaging (Khan et al. 2010). While the effects of chloroquine are quite dramatic in vitro, treatment efficacy in non-human primates and humans has been limited (Roques et al. 2018).

Arbidol or umifenovir is marketed as a prophylactic antiviral treatment against influenza A and B in both Russia and China but inhibits a wide breadth of viruses including Ebola, hepatitis $\mathrm{C}$, and Tacaribe virus. Maximum inhibition of CHIKV occurred when arbidol was added prior to infection with $\mathrm{IC}_{50}$ values ranging from 5 to $10 \mu \mathrm{g} / \mathrm{mL}$ (Delogu et al. 2011). CHIKV resistance selected against arbidol occurs following a single amino acid substitution at G407R of the viral E2 glycoprotein. Mechanistically, the effects of arbidol are hypothesized to occur through disrupting the formation and integrity of cytopathic vacuoles attached to endosomes and lysosome membranes due to arbidol incorporation into these membranes (Blaising et al. 2014). Derivatives of arbidol with increased potency and selectivity index have been synthesized (Di Mola et al. 2014), but additional studies are required to elucidate the mechanism of action for arbidol against CHIKV and to further develop analogs that can extend the antiviral treatment window.

Suramin is a multifunctional polysulfonated small molecule with antiviral, neoplastic, and -nematodal activities and is currently FDA approved for the treatment of trypanosomiasis in humans. Suramin has antiviral activities against a wide variety of viruses including CHIKV (Ho et al. 2015). While multiple mechanisms for suramin activity against CHIKV have been proposed, the compound inhibits viral entry (Albulescu et al. 2015). Interestingly, molecular docking studies indicate that suramin may embed itself into the cavity present in the E1/E2 heterodimer and interfere with their function (Ho et al. 2015). Other lead compounds have been identified using computational docking using the structure for the viral envelop, but testing for antiviral activity of these leads is still pending (Agarwal et al. 2019).

CHIKV fusion and budding are influenced by the lipid composition of the viral envelope and the host cell membrane. This is particularly the case for levels and composition of cholesterol and sphingolipids. Therefore, abnormalities in lipid metabolism can affect CHIKV infection outcomes. For example, depletion of cholesterol with methyl- $\beta$-cyclodextrin prior to CHIKV infection of cells reduces infection by up to $63 \%$ (Bernard et al. 2010). Treatment of human foreskin fibroblasts with either of two cholesterol trafficking inhibitors, U18666A and imipramine, results in a dose-dependent accumulation of intracellular cholesterol and 
inhibition of CHIKV replication (Wichit et al. 2017). Imipramine was demonstrated to inhibit the CHIKV entry/fusion step and impair post-fusion viral RNA replication, suggesting the compound is able to interfere with two different stages of the CHIKV infection process. These results suggest other cholesterol inhibitors may have potential antiviral activities against CHIKV.

\subsection{Inhibitors of CHIKV Structural Proteins}

The outer envelope surface of CHIKV is made up of 80 trimeric spikes created by heterodimers of the E1 and E2 glycoproteins (Voss et al. 2010). E2 facilitates the binding of CHIKV to the surface of the host cell receptors (Weber et al. 2017) and contains a cytoplasmic tail that interacts directly with the viral capsid proteins (Mukhopadhyay et al. 2006). Upon entry, E1, a class II viral fusion protein, mediates fusion of the viral envelope and host cell endosomal membranes (Kielian et al. 2010; Uchime et al. 2013). E3, the third glycoprotein, binds exclusively to E2 forming pE2 (Li et al. 2010). E3 is cleaved from E2 by the host protease furin (Ozden et al. 2008) exposing a $\mathrm{N}$-terminal signal peptide that targets the structural polyprotein toward the ER for initial processing (Strauss and Strauss 1994). E3 E1-E2 dimers can then form in the trans-Golgi network, with proper folding mediated by E3 (Metz and Pijlman 2016a; Wong and Chu 2018). After cleavage, $\mathrm{E} 3$ remains non-covalently linked to the dimers until the neutral $\mathrm{pH}$ of the plasma membrane causes its dissociation. This conformational change exposes the acid-sensitive region between E1 and E2, priming E1 for activation when exposed to low pH (Metz and Pijlman 2016a, b; Uchime et al. 2013).

CHIKV capsid proteins have three domains including: (1) a highly basic region that mediates non-specific RNA interactions while containing nuclear localization and export sequences; (2) a viral genomic RNA-binding region that also promotes capsid oligomerization; and (3) a serine protease capable of cis and trans cleavage of the viral capsid proteins (Metz and Pijlman 2016a; Weiss et al. 1994; Linger et al. 2004; Sokoloski et al. 2017; Aliperti and Schlesinger 1978; Choi et al. 1991; Melancon and Garoff 1987; Thomas et al. 2010). The capsid nuclear localization and export signals allow the protein to shuttle between the nucleus and cytoplasm (Thomas et al. 2013). Mutation of the capsid NES causes nuclear retention and blockage of the nuclear import system, whereas mutation of NLS attenuates the virus (Jacobs et al. 2017; Taylor et al. 2017; Thomas et al. 2013). A hydrophobic domain present in the capsid also directly interacts with the C-terminal tail of E2 to promote assembly and to facilitate budding of CHIKV through the host cell plasma membrane (Sharma et al. 2018). The capsid hydrophobic-binding pocket binds the proline-405 residue of E2, a highly conserved residue in alphaviruses (Aggarwal et al. 2012; Kim et al. 2005). Picolinic acid (PCA), a potent inhibitor of CHIKV, closely resembles the molecular structure of proline. The compound is capable of binding to the hydrophobic pocket of CHIKV capsid (Sharma et al. 2016). Treatment with PCA results in a significant reduction in vRNA levels and infectious 
virus, suggesting possible inhibitory effects on viral disassembly, replication, or nucleocapsid assembly (Sharma et al. 2016). Although the exact mechanism by which it functions remains unclear, the observed antiviral properties of PCA against CHIKV demonstrate the importance of blocking the hydrophobic domain of capsid. CHIKV capsid and protease activity continue to be an under-utilized target for inhibitor development with the potential to be a critical target for CHIKV inhibitors.

\subsection{Inhibitors of CHIKV Non-structural Proteins}

\subsection{1 nsP1}

The nsP1 protein is a viral mRNA capping enzyme with both methyltransferase and guanylyltransferase (GTase) activities. The protein is responsible for capping and methylation of new synthesized viral RNA protecting it from degradation by host exonucleases and directing efficient translation of viral mRNAs (Rupp et al. 2015; Wong and Chu 2018). Additionally, nsP1 plays an important role in RC formation and localization, which is directed by an alpha-helical amphipathic loop and palmitoylation site that allows nsP1 containing RCs to dock to the host cell plasma membrane. This process tethers RCs within spherules (Spuul et al. 2007). nsP1 is involved in the recruitment of other nsPs into spherules required for the formation of functional RCs (Abu Bakar and Ng 2018; Salonen et al. 2003). nsP1 is also involved in releasing budding particles from the cell membrane through interactions with the host protein tetherin (BST-2) (Jones et al. 2013). These functions of nsP1 make it an appealing target for drug discovery as blocking nsP1 functions disrupt RC formation and prevent vRNA synthesis (Abu Bakar and Ng 2018). However, the discovery and design of inhibitors targeting these functions have been difficult due to the lack of definitive structural knowledge about the interactions between nsPs and limited information about the structure of CHIKV spherules.

The most fully characterized inhibitors of CHIKV nsP1 target the GTase function of the capping machinery. MADTP-314 and MADTP-372 are CHIKV and VEEV nsP1 inhibitors that are part of the [1,2,3]trizolo[4,5-d]pyrimidin-7(6 h)ones (MADTP) compound series identified using a cell-based CHIKV replication screen (Gigante et al. 2014, 2017). CHIKV resistance to MADTP-314 occurs through a P34S mutation in nsP1 GTase functional domain that was validated by reverse genetics. In vitro VEEV nsP1 GT assay studies determined that MADTP-372 disrupted GTase activity and downstream capping reactions, which are suggested to occur by either disruption of $\mathrm{m}^{7} \mathrm{GTP}-\mathrm{nsP} 1$ complex formation or inhibition of guanylation (Delang et al. 2016; Gigante et al. 2017). Recently, an HTS was developed to identify compounds that inhibit the formation of the 5' cap by measuring competition for the GTP-binding site on CHIKV nsP1 using fluorescently labeled GTP (Bullard-Feibelman et al. 2016). This method identified the natural compound lobaric acid, as a GTP competitor for nsP1 binding and inhibitor of the guanylation step of the capping reaction (Feibelman et al. 2018). 


\subsection{2 nsP2}

CHIKV nsP2 is a large protein with at least four enzymatic functions including: (1) helicase activity by unwinding double-stranded RNA in the $5^{\prime}$ to $3^{\prime}$ direction; (2) nucleotide triphosphatase (NTPase) activity; (3) RNA 5' triphosphatase activity; and (4) papain-like cysteine protease activity (Rupp et al. 2015; Wong and Chu 2018; Das et al. 2014b; Karpe et al. 2011; Ramakrishnan et al. 2017). Activity of the C-terminal protease domain is responsible for processing the viral nsP1234 polyprotein (Ramakrishnan et al. 2017). Additionally, a portion of nsP2 can localize to the nucleus where it plays a role in the shutoff of host transcription by mediating degradation of the RNA polymerase subunit II Rbp1 (Akhrymuk et al. 2012). nsP2 also mediates the shutoff of host translation by interacting with a number of ribosomal proteins (Strauss and Strauss 1994). Host cell transcriptional and translational shutoffs occur without any obvious negative effects to CHIKV replication. Although mutation of the nsP2 NLS of Semliki Forest virus (SFV) prevented the protein from entering the nucleus; this process also reduced SFV-induced cell death, likely due to a reduction in cytotoxicity associated with host shutoff (Tamm et al. 2008). Nuclear localized nsP2 is also capable of inhibiting innate immunity by suppression of JAK/STAT signaling. Therefore, multiple modes of action may be at play (Bhalla et al. 2016; Breakwell et al. 2007; Frolov et al. 2009; Gorchakov et al. 2005). These antiviral functions of nsP2 have earned the protein designation as a virulence factor as well. Thus, due to these effects on RNA replication and those directed against the host, nsP2 is a valid antiviral target for inhibiting CHIKV. For example, a high-throughput phenotypic screen to identify compounds that target virus-mediated host transcriptional shutoff induced by nsP 2 was developed utilizing a trans-reporter where expression of a luciferase gene is driven by an artificial transcription factor (Lucas-Hourani et al. 2013b). This method successfully identified a natural compound that blocked nsP2 activity and inhibited CHIKV replication.

In recent years, the nsP2 protease function has become a major target of interest due to its essential role in viral replication and the success of FDA-approved inhibitors targeting HIV and HCV proteases (Manns and von Hahn 2013; Pokorna et al. 2009; De Clercq 2007). Peptidomimetic compounds that target nsP2 protease activity have been developed using a number of biochemical tools including a FRET-based protease assay (Singh et al. 2018). The crystal structures of CHIKV and VEEV nsP2 have been solved, and in silico screening for nsP2 protease inhibitors has begun. Millions of small molecule structures have been tested by a variety of virtual screening methods to identify compounds that interact with CHIKV nsP2 protease domain (Bassetto et al. 2013; Agarwal et al. 2015) and to explore the possible mechanism of action of compounds through in silico docking (Jadav et al. 2015). These types of in silico studies have generated a number of promising lead compounds; however, experiments that confirm antiviral activity and/or target specificity are needed to determine whether the in silico identified compounds inhibit by the predicted functions (Abu Bakar and Ng 2018; Dhindwal et al. 2017). Albeit, in silico predicted inhibitors targeting the catalytic site of the 
$\mathrm{nsP} 2$ protease were active in viral inhibition assays and nsP2 protease function assays. Some of the predicted compounds decreased nsP2 protease function, viral RNA synthesis, and release of infectious viral particles (Das et al. 2016). This study supports the feasibility of virtual screens to identify target-specific viral inhibitors.

\subsection{3 nsP3}

The functional role of nsP3 during CHIKV replication is still unclear. Structurally the nsP3 protein is divided into three domains: (1) an N-terminal macrodomain; (2) an alphavirus unique domain (AUD) containing a zinc-binding region; and (3) a C-terminal hypervariable domain (Abu Bakar and Ng 2018). The highly conserved macrodomain is thought to regulate $\mathrm{CHIKV}$ replication through the binding of RNA and ADP-ribose and ADP-ribosyl hydrolase activities (Malet et al. 2009; McPherson et al. 2017; Abraham et al. 2018). These activities confer efficient CHIKV replication, indicating a need for the virus to evade host ADP-ribosylation of proteins or RNA but how this is important is still unclear. The highly conserved nature of the macrodomain and residues of the ADP-ribose-binding pocket within the alphavirus family and other RNA viruses makes it an ideal site for further development of macrodomain-specific antivirals. Using computer-aided design, we have screened a small fragment compound library to identify small molecules that bind within the ADP-ribose-binding pocket of the CHIKV macrodomain. We validated one fragment through crystal soaking and NMR. However, the small size of the fragments prohibits their utility as inhibitors in cell-based assays. We are currently utilizing computer-aided design to build larger fragments that increase their specificity and activity as CHIKV inhibitors. Other in silico studies aimed at similarly identifying small molecule inhibitors of the macrodomain ADP binding identified both naturally occurring small molecules (flavonoids) and pharmaceutical compounds with the potential to bind CHIKV nsP3 including the flavonoid naringenin (Nguyen et al. 2014; Pohjala et al. 2011; Seyedi et al. 2016).

Recent mutational studies of the CHIKV AUD suggest this domain determines species specificity and plays a key role in virus genome and RNA transcription assembly (Gao et al. 2019). Mutation of the AUD impaired subgenomic RNA synthesis, RNA-binding activity of the domain, and subcellular localization of nsP3 during CHIKV replication, in turn reducing virus production. This analysis highlights the potential for the nsP3 AUD as an antiviral target. nsP3 proteins from other alphaviruses reportedly interact with a diverse range of host factors including sphingosine kinase 2 (SK2), Hsp90B, PI3K-AKT-mTOR pathway, and IkkB with mostly proviral outcomes (Lark et al. 2017), further supporting future investigations into their utility as antiviral targets by disruption of these virus-host protein interactions necessary to enhance virus replication. The $\mathrm{C}$-terminal domain promotes CHIKV replication by interfering with stress granule formation through interactions with GTPase-activating protein (SH3 domain)-binding protein 1 (G3BP1) (Panas et al. 2012, 2014; Fros et al. 2012) and the mosquito version of G3BP1 called Rasputin (Fros et al. 2015). The heat shock protein Hsp-90 has also 
been shown to interact with nsP3, but the role in virus replication is still unclear (Rathore et al. 2014). Despite the many potential target sites and key host and viral interactions of nsP3, only a limited number of studies have focused on developing antivirals targeting nsP3.

\subsection{4 nsP4}

The alphavirus RNA-dependent RNA polymerase ( $\mathrm{RdRp}$ ) is encoded within nsP4, and this protein is the most highly conserved in the alphavirus family (Rupp et al. 2015; Weston et al. 2005; Pietila et al. 2017). Alphavirus RdRps are responsible for the replication of the viral genome and subgenomic transcripts. As part of the P123 early replication complex, nsP4 mediates the synthesis of the negative genomic strand from the incoming genome (Pietila et al. 2017). Once fully active, the RC complex containing the polymerase shifts to the synthesis of the $49 \mathrm{~S}$ genomic RNA and $26 \mathrm{~S}$ subgenomic RNA from these negative strand templates. nsP4 N-terminal domain also contains adenylyltransferase (TATase) activity, which was identified through mutational studies that indicated a role in adding or maintaining the 3' poly-A tail at the end of the genome (Rubach et al. 2009; Tomar et al. 2006). The $\mathrm{N}$-terminal domain of nsP4 also contains an alphavirus-specific domain that is important for the interaction with the P123 complex and formation of RCs. Deletion of the $97 \mathrm{~N}$-terminal residues prevents de novo RdRp activity regardless of the presence of P123 as well as the association with the P123 complex. This finding suggests that this region of nsP4 may be a valid target for small molecule inhibitor development (Rubach et al. 2009; Tomar et al. 2006). nsP4 also interacts with the host protein Hsp90 $\alpha$ via an unknown mechanism and, as mentioned above, inhibition of Hsp90 $\alpha$ decreases viral RNA and protein synthesis (Rathore et al. 2014).

Due to their unique structure, RNA virus RdRp is an important target for drug development. As such a number of compounds have been developed that block RNA virus replication. Initially developed as an anti-influenza virus inhibitor, favipiravir (T-705) has also shown good activity against many other divergent RNA virus polymerases including those encoded by alphaviruses (Furuta et al. 2017). However, T-705 is not active against DNA or DNA-dependent RNA polymerases making it selective to both plus and minus strand RNA viruses. Favipiravir is quickly converted into the triphosphate active form within cells, which is recognized as a substrate for the viral RdRp (Furuta et al. 2005). Functionally T-705 competitively inhibits the incorporation of ATP and GTP by the RdRp leading to chain termination (Delang et al. 2014; Furuta et al. 2013). T-1105 is a T-705 analog that effectively inhibits CHIKV nsP4 through interactions with the Lys-291 residue. T-705 is active against a wide variety of alphaviruses and other RNA viruses, potentially because the Lys-291 residue is conserved in the polymerases of positive-sense RNA viruses (Delang et al. 2014). $\quad \beta$-D-N $\mathrm{N}^{4}$-hydroxycytidine (NHC) is another nucleoside analog that targets viral RdRps. These types of nucleosides tend to work potently and for the development of even low-level resistance against NHC, the alphavirus VEEV requires the acquisition of multiple 
cooperative mutations within the RdRp domain of nsP4 (Urakova et al. 2018). The FDA-approved drug Sofosbuvir is a UMP prodrug that gets converted to the active form in cells where it acts as a chain terminator for flavivirus RNA polymerases. Sofosbuvir was validated to also bind CHIKV nsP4 and inhibit RNA synthesis and virus replication in cultured cells and in vivo (Ferreira et al. 2019). NHC is also capable of inhibiting CHIKV replication (Ehteshami et al. 2017). In addition to these nucleoside analogs, HTS of chemical compound libraries identified a non-nucleoside benzimidazole compound possessing inhibitory activity against nsP4 (Wada et al. 2017). This compound inhibited the RdRp function of nsP4 by targeting residue Met-2295, potentially inhibiting the RdRp's ribonucleotide selection function (Wada et al. 2017). The potential is high for developing other nucleoside analogs or compounds that target alphavirus nsP4.

\subsection{Inhibitors of CHIKV RNA Genome Replication}

During replication, the viral RNA genome is first converted to the minus strand utilizing the $\mathrm{P} 123 / \mathrm{nsP} 4$ complex. Once fully processed, the replication complex then mediates synthesis of the full-length genomic RNA (plus strand) as well as the subgenomic RNA. Targeting of many different nsP functions, as described above, can have pleiotropic effects on viral replication including vRNA synthesis. However, there are also a number of broad-spectrum RNA genome replication inhibitors described with activity against CHIKV. One of the first to be described is Ribavirin, which is a broad-spectrum antiviral that has already been approved for the treatment of RSV in infants and chronic hepatitis C infections (Pawlotsky 2014; Turner et al. 2014). Ribavirin has demonstrated antiviral activity against CHIKV and exhibited synergism with both doxycycline and IFN- $\alpha$ (Briolant et al. 2004; Rothan et al. 2015). Mechanistically, ribavirin is a guanosine analog, with the major proposed biomechanisms for inhibition of RNA viruses including interference with inosine monophosphate dehydrogenase (IMPDH) function leading to depletion of GTP pools (Leyssen et al. 2006), as well as inhibition of viral RNA capping (Paeshuyse et al. 2011). Other possible mechanisms include an increased mutation rate as a result of the incorporation of ribavirin by the RdRp (Paeshuyse et al. 2011). Additional studies to determine the mechanism leading to ribavirin inhibition of CHIKV are ongoing, but it is important to note that it is effective only during the early stages of the CHIKV replication cycle (Mishra et al. 2016).

RNA viruses are highly mutable making them capable of developing resistance to small molecules. However, due to this relatively high mutation rate most RNA virus polymerases are unable to detect or repair damaged or altered nucleotides. This fact allows one to design nucleotide analogs as either chain terminators or ones that increase the mutation frequency above tolerable rates so that the virus becomes genetically unstable. A broad-spectrum viral genome replication inhibitor is the uridine analog 6-azauridine. Compared to ribavirin, 6-azauridine is more effective against CHIKV in infected cells (Briolant et al. 2004; Pohjala et al. 2011). Similar 
to other nucleoside analogs, 6-azauridine most likely interferes with cellular UTP metabolism and the nucleoside analog incorporates into CHIKV RNA leading to genome error catastrophe (Rada and Dragun 1977; Scholte et al. 2013). While 6-azauridine has been approved for clinical use against psoriasis, further testing in animal models of viral infection is needed to examine in vivo antiviral activity (Deneau and Farber 1975; Crutcher and Moschella 1975).

\section{Targeting Host Factors Involved in CHIKV Replication}

The ability of viruses to rapidly evolve and select for resistant mutations to single antiviral treatments makes it necessary to identify antiviral drug cocktails containing individual compounds that lack overlapping resistance markers to increase therapeutic efficacy. Another way to reduce antiviral resistance is to target host proteins or processes required for virus replication. Development of host-targeting antivirals has another advantage in that they may have increased breadth of antiviral activity for viruses that share a cellular pathway. For example, harringtonine and its analogs homoharringtonine and cephalotaxine alkaloids were identified using an immunofluorescence-based screen of small molecule inhibitors derived from natural products to have potent anti-CHIKV activity (Kaur et al. 2013). Harringtonine functions as an inhibitor of eukaryotic translation by blocking the large ribosomal subunit (Fresno et al. 1977). The compound also inhibits translation of EpsteinBarr virus and influenza virus and has been used for translational profiling experiments (Bencun et al. 2018; Machkovech et al. 2019). Harringtonine blocked translation of CHIKV nsPs and inhibited viral RNA synthesis and subsequent production of structural proteins, indicating that the compound inhibits early viral translation events (Kaur et al. 2013). Resistance to harringtonine has yet to be reported for any virus. It is important to keep in mind the potential for off-target effects and isoform specificity that can limit host-directed antivirals especially for in vivo use.

Different screening methods have been used to identify CHIKV/host interactions important for the virus lifecycle. Linking the results from a human whole genome-wide loss-of-function siRNA screen with a drug repurposing database search was used to rapidly identify small molecule inhibitors of CHIKV (Karlas et al. 2016). In the CHIKV/HEK-293 cell loss-of-function screen, knockdown of 156 host genes increased virus replication, whereas 41 displayed antiviral activity. To identify potential antiviral small molecule inhibitors, the validated proviral factors were used to screen available databases that link their drugs to their experimentally validated target proteins. Using this process, 20 compounds were identified that interact with gene products of $14 \mathrm{CHIKV}$ proviral factors that span six unique pathways including vacuolar-type H+ ATPase, CDD-like kinase 1 (CLK1), fms-related tyrosine kinase 4 (FLT4) calmodulin signaling, fatty acid synthesis, and lysine acetyltransferase 5 (KAT5). All 20 compounds inhibit CHIKV replication but, as expected, some display cytotoxicity. A combination regimen 
containing TOFA, a fatty acid synthesis inhibitor, and the calmodulin inhibitor pimozide showed increased inhibition of CHIKV and significantly reduced CHIKV-induced footpad swelling (Karlas et al. 2016). As discussed below, research into host factors involved in CHIKV replication has identified additional potential inhibitors of virus replication and disease.

\subsection{Protease Inhibitors}

Host proteases are a diverse group of enzymes that catalyze the cleavage of the same or other proteins. The three large groupings of proteases include serine, cysteine, and metalloproteinases. The proteases recognize specific substrate amino acid sequences and perform cleavage of the scissile bond. Host furin is a serine-like protease that processes a number of different substrates including host-derived proalbumin and transforming growth factor beta. However, as a resident of the TGN, furin also cleaves a number of viral glycoproteins including tick-borne encephalitis virus, HIV gp160, and HCMV gB; and this process typically activates these proteins (Hallenberger et al. 1992; Stangherlin et al. 2017). Similarly, furin is involved in processing of the alphavirus envelope $\mathrm{pE} 2 / \mathrm{E} 3$ precursor at short multibasic motifs during virion transport through the TGN (Klimstra et al. 1999; Ozden et al. 2008). This processing event is required for the formation of infectious particles for many alphaviruses including CHIKV, which validates furin as an antiviral target (Heidner et al. 1994, 1996; Klimstra et al. 1999). The irreversible furin inhibiting peptide decanoyl-RVKR-chloromethyl-ketone (Dec-RVKR-cmk) significantly inhibits CHIKV infection in human muscle satellite cells by impairing the formation of mature virus particles (Ozden et al. 2008). Interestingly, therapy combining dec-RVKR-cmk with chloroquine had additive effects resulting in a near-complete suppression of virus spread and yield when added just prior to CHIKV infection. Obvious issues with selectivity and toxicity related to the plethora of cellular furin cleavage substrates as well as the large size of current furin inhibitors will need to be considered when assessing the antiviral therapeutic value for inhibitors of furin (Subudhi et al. 2018).

\subsection{Pyrimidine and Purine Synthesis Inhibitors}

RNA viruses rely heavily on the host pool of nucleosides for efficient replication. Changes in the concentration of ribonucleotide triphosphate pools can influence the ability of the RNA virus to replicate and possibly increase mutation frequency (Ortiz-Riano et al. 2014). A number of HTS campaigns have identified inhibitors of pyrimidine synthesis as potent antivirals with broad activity (Lucas-Hourani et al. 2013a; Chung et al. 2016; Hoffmann et al. 2011; Smee et al. 2012; Wang et al. 2011). The small molecule DD264 was identified through a cell-based HTS assay to 
identify molecules that stimulate the interferon response, and through mechanism of action, experiments were identified as an inhibitor of de novo pyrimidine synthesis suggesting a unique link between the interferon response and pyrimidine biosynthesis (Lucas-Hourani et al. 2013a). DD264 inhibition of virus replication was dependent upon the activation of IRF1 suggesting an important role in innate immune activation. Interestingly, DD264 inhibition of CHIKV was blocked when the pyrimidine uridine but not purine guanosine was added to the culture medium also supporting that lowered pyrimidine levels are responsible for the activity of DD264. Dihydroorotate dehydrogenase (DHODH), the fourth enzyme in the pyrimidine biosynthetic pathway, was identified as the target of DD264. DD264 has proven to be a useful tool to better understand the link between the innate immune response and pyrimidine biosynthesis during CHIKV replication. Targeting the mitochondrial electron transport with antimycin A also inhibits de novo pyrimidine synthesis resulting in a broad-spectrum antiviral effect (Raveh et al. 2013). Compounds that target purine biosynthesis have similar antiviral properties against CHIKV. Mycophenolic acid (MPA) inhibits the cellular enzyme inosine monophosphate dehydrogenase that is required for guanine synthesis. MPA inhibits CHIKV replication by blocking viral genome synthesis (Khan et al. 2011). The in vivo therapeutic application of pyrimidine biosynthesis inhibitors is complicated by the high uridine concentration in the body that can negate the antiviral effects, but there may be a utility as site-specific antiviral treatments.

\subsection{Cellular Kinase Inhibitors}

Viruses modify host kinase signaling pathways in order to adjust the host environment to promote their replication (Keating and Striker 2012). The PI3K-AKT-mTOR pathway is involved in cell survival and alphaviruses activate this pathway. Semliki Forest virus nsP3 directly activates AKT at the plasma membrane where it is probably involved in the formation of the replication complex (Spuul et al. 2010). However, this effect might be virus-specific since CHIKV replication complex formation was not dependent upon this pathway (Thaa et al. 2015). CHIKV nsP3 is also involved in recruiting sphingosine kinase to the replication complex (Reid et al. 2015). There are a number of high-throughput methods that have been used to identify additional host kinases and signaling pathways involved in CHIKV replication and potential inhibitors. HTS screens utilizing kinase inhibitor libraries such as the BioFocus kinase inhibitor library identified six lead hit compounds with the most potent compound CND3514 a thiozole-4-carboxaminde core scaffold inhibitor with an $\mathrm{EC}_{50}=2.2 \mu \mathrm{M}$ (Cruz et al. 2013). Other approaches including genome wide or kinase focused siRNA library screens have also been used (Reid et al. 2015). The use of multiplexed inhibitor beads to profile changes in the kinome has also been employed to identify kinases relevant to CHIKV replication (Broeckel et al. 2019). Through this process, changes in the abundance/activity of the Src family kinase (SFK)- 
phosphatidylinositol 3-kinase (PI3K)-AKT-mTORC signaling pathway during the course of CHIKV were discovered. Inhibition of this pathway with the SFK inhibitor dasatinib blocked replication of CHIKV and multiple other alphaviruses in human fibroblasts. In mechanism of action studies, dasatinib was found to block CHIKV subgenomic RNA translation, significantly reducing structural protein levels, without affecting synthesis of viral genomic or subgenomic RNA (Broeckel et al. 2019). A similar effect was observed with the mTORC1/2 inhibitor Torin. These results were in part due to a decreased amount of CHIKV RNA associated with polysomes during replication, suggesting CHIKV relies on SFKs for structural protein synthesis (Broeckel et al. 2019).

Protein kinase $\mathrm{C}(\mathrm{PKC})$ is a serine/threonine kinase that is recruited to the plasma membrane upon cellular activation in response to a number of stimuli. PKC may play a role in early viral entry steps that involve endosomal trafficking. Inhibition of PKC with H-7 blocked entry for a number of enveloped viruses including Sindbis virus (Constantinescu et al. 1991). PKC modulators have also been tested for their ability to inhibit CHIKV replication. Prostratin and 12-O-tetradecanoylphorbol-13-acetate (TPA) inhibited CHIKV replication in Vero cells but TPA may be CHIKV-specific as it fails to block other alphaviruses (Bourjot et al. 2012). Aplysiatoxin analogs, known PKC activators, debromoaplysiatoxin and 3-methoxydebromoaplysiatoxin were also reported to inhibit CHIKV (Gupta et al. 2014). The pan-PKC modulator byrostatin 21 also potently inhibited CHIKV replication without modulating the cellular PKC pathways, which suggest that these compounds may also work through PKC-independent pathways. (Staveness et al. 2016). Deciphering the mechanisms of how PKC modulates the CHIKV lifecycle requires further investigation. Similar to the other host targeted antivirals discussed, the clinical use of PKC modulators will be limited because of the importance of PKC in normal cell survival. Additional studies are required to fully elucidate the specific cellular kinase pathways involved in CHIKV replication in order to fully explore the development of novel small molecule antivirals.

\subsection{Inhibitors of Protein Chaperones}

Cytoplasmic proteins and those traversing through the cellular secretory compartment require chaperones for proper folding and disulfide bond formation that is important for proper trafficking, increased stability, and improved function. Two categories of chaperones have been shown to be involved in CHIKV replication including the Heat shock protein-90 (Hsp-90) and protein disulfide isomerases (PDI). For example, Hsp-90 is a highly abundant chaperone that is utilized by both cellular and viral proteins to ensure proper folding, maturation, localization, and turnover of substrate proteins. Hsp-90 plays an important role in the replication of many RNA and DNA viruses making it a possible target for broad-spectrum antiviral development. The Hsp-90 inhibitor geldanamycin and synthetic analogs of geldanamycin HS-10 and SNX-2112 all inhibit CHIKV replication 
(Rathore et al. 2014). Geldanamycin inhibition has shown that Hsp-90 is essential during the early stages of CHIKV replication by promoting nsP2 stability (Das et al. 2014a). Hsp-90 also interacts with CHIKV nsP3 and nsP4, and Hsp-90 $\alpha$ may play an important role in the stabilization of $\mathrm{nsP} 4$ and formation of the replication complex (Rathore et al. 2014). HS-10 and SNX-2112 treatment significantly reduced serum viral titers at $48 \mathrm{hpi}$ and decreased CHIKV-induced joint swelling disease and inflammatory cytokine production in SVA129 infected mice (Rathore et al. 2013). However, the development of Hsp-90 inhibitors for in vivo use has been difficult because the chaperone is involved in many cellular processes and signaling pathways that can cause a certain level of cytotoxicity when inhibited. A recently developed second-generation Hsp-90 inhibitor called Ganetespib has decreased cytotoxicity and in vivo safety (Jhaveri and Modi 2015).

Inhibitors of cellular PDIs block CHIKV infection by decreasing the infectivity per particle ratio of secreted viruses (Langsjoen et al. 2017). Since CHIKV E1 and E2 glycoproteins require specific disulfide bonding patterns between conserved cysteine residues, the reduction in infectivity is likely to require host PDI for envelope protein function. Consistent with this hypothesis, PDI inhibitors decreased cell-cell fusion events facilitated by E1. Auranofin, an FDA-approved thioredoxin reductase (TRX-R) inhibitor, was the most promising compound with a therapeutic index of 104.5 at $12 \mathrm{hpi}$, and was efficacious in mouse models of CHIKV infection and disease (Langsjoen et al. 2017).

\section{Conclusions}

The development of inhibitors against Chikungunya virus is critical for treating infected patients to prevent or reduce transmission and disease. CHIKV remains a clinically relevant human pathogen due to the severity and chronicity of disease and explosive nature of viral epidemics. Recent development of inhibitors against CHIKV has identified a number of viable viral and cellular targets that, when blocked, can robustly inhibit virus replication. However, there are a number of challenges that remain to overcome in order to successfully treat patients. For example, the virus rapidly mutates indicating that the virus can quickly develop resistance to most single-drug regimens. This would indicate that two or more drugs that target unique aspects of virus replication are required to limit resistance that would render the drug ineffective. Another major issue that needs to be addressed is the aspect of determining what the therapeutic window is for treating CHIKV infection and disease. Due to the chronicity of the viral infection and disease, when testing new antivirals, it is important to not only assess efficacy during the acute phase but also the chronic phase in order to establish the effective therapeutic window. The process of developing inhibitors and identifying the antiviral targets will continue to also improve our understanding of the virus lifecycle (Table 1). 
Table 1 Viral and host-directed antivirals against Chikungunya virus

\begin{tabular}{|c|c|c|c|}
\hline Compound & Target/MOA & $\begin{array}{l}\text { Validation } \\
\text { method }\end{array}$ & References \\
\hline \multicolumn{4}{|c|}{ Inhibitors of CHIKV entry } \\
\hline FL23/FL3 & Entry & In vitro & Wintachai et al. (2015) \\
\hline EGCG & Entry & In vitro & Weber et al. (2015) \\
\hline Chloroquine & Entry & In vitro & Khan et al. (2010) \\
\hline Arbidol/Emifenovir & Entry & In vitro & Delogu et al. (2011) \\
\hline $\begin{array}{l}\text { IIIe 7/IIIf } \\
\text { (Arbidol derivatives) }\end{array}$ & Entry & In vitro & Di Mola et al. (2014) \\
\hline Imipramine & Entry & In vitro & Wichit et al. (2017) \\
\hline U18666A & Entry & In vitro & Wichit et al. (2017) \\
\hline Suramin & Entry & In vitro & Ho et al. (2015) \\
\hline \multicolumn{4}{|c|}{ Inhibitors of CHIKV structural proteins } \\
\hline Picolinic acid & Capsid protein & In vitro & Sharma et al. (2016) \\
\hline \multicolumn{4}{|c|}{ Inhibitors of CHIKV non-structural proteins } \\
\hline \multicolumn{4}{|l|}{$n s P 1$} \\
\hline MADTP & nsP1 & In vitro & $\begin{array}{l}\text { Delang et al. (2016), } \\
\text { Gigante et al. (2014, } \\
\text { 2017) }\end{array}$ \\
\hline Lobaric acid & nsP1 & In vitro & $\begin{array}{l}\text { Feibelman et al. } \\
\text { (2018) }\end{array}$ \\
\hline \multicolumn{4}{|l|}{$n s P 2$} \\
\hline $2 \mathrm{E}$ & nsP2 & $\begin{array}{l}\text { In silico/ } \\
\text { in vitro }\end{array}$ & $\begin{array}{l}\text { Bassetto et al. (2013), } \\
\text { Das et al. (2016) }\end{array}$ \\
\hline IDI452-2 & nsp2 & In vitro & $\begin{array}{l}\text { Lucas-Hourani et al. } \\
\text { (2013b) }\end{array}$ \\
\hline NCL1610 & nsP2 & In silico & Nguyen et al. (2015) \\
\hline ZINC67680487 & nsP2 & In silico & Jadav et al. (2015) \\
\hline ZINV0472520 & nsP2 & $\begin{array}{l}\text { In silico/ } \\
\text { in vitro }\end{array}$ & Jadav et al. (2017) \\
\hline \multicolumn{4}{|l|}{$n s P 3$} \\
\hline Naringenin & nsp3 & \begin{tabular}{|l} 
In silico/ \\
in vitro
\end{tabular} & $\begin{array}{l}\text { Pohjala et al. (2011), } \\
\text { Seyedi et al. (2016) }\end{array}$ \\
\hline NCA_25457 & nsp3 & In silico & Nguyen et al. (2014) \\
\hline NC_345647 & nsp3 & In silico & Nguyen et al. (2014) \\
\hline \multicolumn{4}{|l|}{$n s P 4$} \\
\hline Favipiravir (T705) & nsP4 & \begin{tabular}{|l|} 
In vitro/ \\
in vivo
\end{tabular} & Delang et al. (2014) \\
\hline B NHC & nsP4 & In vitro & $\begin{array}{l}\text { Ehteshami et al. } \\
\text { (2017) }\end{array}$ \\
\hline Compound A & nsP4 & In vitro & Wada et al. (2017) \\
\hline
\end{tabular}


Table 1 (continued)

\begin{tabular}{|c|c|c|c|}
\hline Compound & Target/MOA & $\begin{array}{l}\text { Validation } \\
\text { method }\end{array}$ & References \\
\hline \multicolumn{4}{|c|}{ Inhibitors of CHIKV RNA genome replication } \\
\hline Ribavirin & \begin{tabular}{|l|}
$\begin{array}{l}\text { Nucleoside } \\
\text { analog }\end{array}$ \\
\end{tabular} & In vitro & $\begin{array}{l}\text { Briolant et al. (2004), } \\
\text { Pohjala et al. (2011) } \\
\end{array}$ \\
\hline 6-Azauridine & $\begin{array}{l}\text { Nucleoside } \\
\text { analog }\end{array}$ & In vitro & $\begin{array}{l}\text { Briolant et al. (2004), } \\
\text { Pohjala et al. (2011) }\end{array}$ \\
\hline \multicolumn{4}{|l|}{ Host-targeting compounds } \\
\hline Pimozide & Calmodulin & $\begin{array}{l}\text { In vitro/ } \\
\text { in vivo }\end{array}$ & Karlas et al. (2016) \\
\hline TOFA & $\begin{array}{l}\text { Fatty acid } \\
\text { synthesis }\end{array}$ & $\begin{array}{l}\text { In vitro/ } \\
\text { in vivo }\end{array}$ & Karlas et al. (2016) \\
\hline Dec-RVKR-cmk & Furin & In vitro & Ozden et al. (2008) \\
\hline \multicolumn{4}{|c|}{ Pyrimidine and purine synthesis inhibitors } \\
\hline DD264 & \begin{tabular}{|l|} 
De novo \\
pyrimidine \\
biosynthesis
\end{tabular} & In vitro & $\begin{array}{l}\text { Lucas-Hourani et al. } \\
\text { (2013a) }\end{array}$ \\
\hline Mycophenolic acid & $\begin{array}{l}\text { Guanine } \\
\text { synthesis }\end{array}$ & In vitro & Khan et al. (2011) \\
\hline \multicolumn{4}{|l|}{ Inhibitors of cellular kinases } \\
\hline CND3514 & Kinase & In vitro & Cruz et al. (2013) \\
\hline Dasatinib & $\begin{array}{l}\text { Src family } \\
\text { kinases }\end{array}$ & In vitro & Broeckel et al. (2019) \\
\hline Torin & mTORC $1 / 2$ & In vitro & Broeckel et al. (2019) \\
\hline Prostratin & PKC & In vitro & Bourjot et al. (2012) \\
\hline 12-O-tetradecanoylphorbol-13-acetate & PKC & In vitro & Bourjot et al. (2012) \\
\hline Debromoaplysiatoxin & PKC & In vitro & Gupta et al. (2014) \\
\hline 3-Methoxydebromoaplysiatoxin & PKC & In vitro & Gupta et al. (2014) \\
\hline Bryostatin-21 & PKC & In vitro & Staveness et al. (2016) \\
\hline \multicolumn{4}{|l|}{ Inhibitors of protein chaperones } \\
\hline Geldanamycin & Hsp-90 & In vitro & Rathore et al. (2014) \\
\hline HS-10 & Hsp-90 & $\begin{array}{l}\text { In vitro/ } \\
\text { in vivo }\end{array}$ & Rathore et al. (2014) \\
\hline 17-AAG & Hsp-90 & $\begin{array}{l}\text { In vitro/ } \\
\text { in vivo }\end{array}$ & Nayak et al. (2017) \\
\hline SNX-2112 & Hsp-90 & $\begin{array}{l}\text { In vitro/ } \\
\text { in vivo }\end{array}$ & Rathore et al. (2014) \\
\hline Auranofin & $\begin{array}{l}\text { Thioredoxin } \\
\text { reductase }\end{array}$ & $\begin{array}{l}\text { In vitro/ } \\
\text { in vivo }\end{array}$ & Langsjoen et al. (2017) \\
\hline PACMA31 & \begin{tabular}{|l} 
Protein \\
disulfide \\
isomerase
\end{tabular} & $\begin{array}{l}\text { In vitro/ } \\
\text { in vivo }\end{array}$ & Langsjoen et al. (2017) \\
\hline
\end{tabular}


Acknowledgements We would like to thank Andrew Townsend for graphical work included in Fig. 2 and Patricia Smith for editorial comments to the manuscript. This work was supported by a grant from the National Institutes of Health (1U19AI109680-01).

\section{References}

Abraham R, Hauer D, McPherson RL, Utt A, Kirby IT, Cohen MS et al (2018) ADP-ribosyl-binding and hydrolase activities of the alphavirus nsP3 macrodomain are critical for initiation of virus replication. Proc Natl Acad Sci USA. 115(44):E10457-E66. https://doi. org/10.1073/pnas.1812130115

Abu Bakar F, Ng LFP (2018) Nonstructural proteins of alphavirus-potential targets for drug development. Viruses 10(2). https://doi.org/10.3390/v10020071

Agarwal G, Gupta S, Gabrani R, Gupta A, Chaudhary VK, Gupta V (2019) Virtual screening of inhibitors against envelope glycoprotein of Chikungunya virus: a drug repositioning approach. Bioinformation 15(6):439-447. https://doi.org/10.6026/97320630015439

Agarwal T, Asthana S, Bissoyi A (2015) Molecular modeling and docking study to elucidate novel Chikungunya virus nsP2 protease inhibitors. Indian J Pharm Sci 77(4):453-460

Aggarwal M, Tapas S, Preeti, Siwach A, Kumar P, Kuhn RJ et al (2012) Crystal structure of aura virus capsid protease and its complex with dioxane: new insights into capsid-glycoprotein molecular contacts. PLoS One 7(12):e51288. https://doi.org/10.1371/journal.pone.0051288

Akhrymuk I, Kulemzin SV, Frolova EI (2012) Evasion of the innate immune response: the old world alphavirus nsP2 protein induces rapid degradation of Rpb1, a catalytic subunit of RNA polymerase II. J Virol 86(13):7180-7191. https://doi.org/10.1128/JVI.00541-12

Albulescu IC, van Hoolwerff M, Wolters LA, Bottaro E, Nastruzzi C, Yang SC et al (2015) Suramin inhibits Chikungunya virus replication through multiple mechanisms. Antiviral Res 121:39-46. https://doi.org/10.1016/j.antiviral.2015.06.013

Aliperti G, Schlesinger MJ (1978) Evidence for an autoprotease activity of sindbis virus capsid protein. Virology 90(2):366-369. https://doi.org/10.1016/0042-6822(78)90321-5

Bandeira AC, Campos GS, Sardi SI, Rocha VF, Rocha GC (2016) Neonatal encephalitis due to Chikungunya vertical transmission: first report in Brazil. IDCases 5:57-59. https://doi.org/10. 1016/j.idcr.2016.07.008

Barton DJ, Sawicki SG, Sawicki DL (1991) Solubilization and immunoprecipitation of alphavirus replication complexes. J Virol 65(3):1496-1506

Bassetto M, De Burghgraeve T, Delang L, Massarotti A, Coluccia A, Zonta N et al (2013) Computer-aided identification, design and synthesis of a novel series of compounds with selective antiviral activity against Chikungunya virus. Antiviral Res 98(1):12-18. https://doi. org/10.1016/j.antiviral.2013.01.002

Bencun M, Klinke O, Hotz-Wagenblatt A, Klaus S, Tsai MH, Poirey R et al (2018) Translational profiling of B cells infected with the Epstein-Barr virus reveals 5' leader ribosome recruitment through upstream open reading frames. Nucleic Acids Res 46(6):2802-2819. https://doi.org/ $10.1093 /$ nar/gky129

Bernard E, Solignat M, Gay B, Chazal N, Higgs S, Devaux C et al (2010) Endocytosis of Chikungunya virus into mammalian cells: role of clathrin and early endosomal compartments. PLoS ONE 5(7):e11479. https://doi.org/10.1371/journal.pone.0011479

Bhalla N, Sun C, Metthew Lam LK, Gardner CL, Ryman KD, Klimstra WB (2016) Host translation shutoff mediated by non-structural protein 2 is a critical factor in the antiviral state resistance of Venezuelan equine encephalitis virus. Virology 496:147-165. https://doi.org/10. 1016/j.virol.2016.06.005

Bhat SM, Mudgal PP, Sudheesh N, Arunkumar G (2019) Spectrum of candidate molecules against Chikungunya virus - an insight into the antiviral screening platforms. Expert Rev Anti Infect Theory 17(4):243-264. https://doi.org/10.1080/14787210.2019.1595591 
Blaising J, Polyak SJ, Pecheur EI (2014) Arbidol as a broad-spectrum antiviral: an update. Antiviral Res 107:84-94. https://doi.org/10.1016/j.antiviral.2014.04.006

Borgherini G, Poubeau P, Jossaume A, Gouix A, Cotte L, Michault A et al (2008) Persistent arthralgia associated with Chikungunya virus: a study of 88 adult patients on reunion island. Clin Infect Dis 47(4):469-475

Bourjot M, Delang L, Nguyen VH, Neyts J, Gueritte F, Leyssen P et al (2012) Prostratin and 12$O$-tetradecanoylphorbol 13-acetate are potent and selective inhibitors of Chikungunya virus replication. J Nat Prod 75(12):2183-2187. https://doi.org/10.1021/np300637t

Breakwell L, Dosenovic P, Karlsson Hedestam GB, D'Amato M, Liljestrom P, Fazakerley J et al (2007) Semliki Forest virus nonstructural protein 2 is involved in suppression of the type I interferon response. J Virol 81(16):8677-8684

Briolant S, Garin D, Scaramozzino N, Jouan A, Crance JM (2004) In vitro inhibition of Chikungunya and Semliki Forest viruses replication by antiviral compounds: synergistic effect of interferon-alpha and ribavirin combination. Antiviral Res 61(2):111-117

Broeckel R, Sarkar S, May NA, Totonchy J, Kreklywich CN, Smith P et al (2019) Src Family kinase inhibitors block translation of alphavirus Subgenomic mRNAs. Antimicrob Agents Chemother 63(4). https://doi.org/10.1128/aac.02325-18

Bullard-Feibelman KM, Fuller BP, Geiss BJ (2016) A sensitive and robust high-throughput screening assay for inhibitors of the Chikungunya virus nsP1 capping enzyme. PLoS ONE 11 (7):e0158923. https://doi.org/10.1371/journal.pone.0158923

Cassadou S, Boucau S, Petit-Sinturel M, Huc P, Leparc-Goffart I, Ledrans M (2014) Emergence of Chikungunya fever on the French side of Saint Martin island, October-December 2013. Euro Surveill 19(13). https://doi.org/10.2807/1560-7917.es2014.19.13.20752

Chang SY, Bae SJ, Lee MY, Baek SH, Chang S, Kim SH (2011) Chemical affinity matrix-based identification of prohibitin as a binding protein to anti-resorptive sulfonyl amidine compounds. Bioorg Med Chem Lett 21(2):727-729. https://doi.org/10.1016/j.bmcl.2010.11.123

Charrel RN, de Lamballerie X, Raoult D (2007) Chikungunya outbreaks-the globalization of vectorborne diseases. N Engl J Med 356(8):769-771. https://doi.org/10.1056/NEJMp078013

Cho B, Jeon BY, Kim J, Noh J, Kim J, Park M et al (2008) Expression and evaluation of Chikungunya virus E1 and E2 envelope proteins for serodiagnosis of Chikungunya virus infection. Yonsei Med J 49(5):828-835. https://doi.org/10.3349/ymj.2008.49.5.828

Choi HK, Tong L, Minor W, Dumas P, Boege U, Rossmann MG et al (1991) Structure of Sindbis virus core protein reveals a chymotrypsin-like serine proteinase and the organization of the virion. Nature 354(6348):37-43. https://doi.org/10.1038/354037a0

Chopra A, Anuradha V, Ghorpade R, Saluja M (2012) Acute Chikungunya and persistent musculoskeletal pain following the 2006 Indian epidemic: a 2-year prospective rural community study. Epidemiol Infect 140(5):842-850. https://doi.org/10.1017/ S0950268811001300

Chung DH, Golden JE, Adcock RS, Schroeder CE, Chu YK, Sotsky JB et al (2016) Discovery of a broad-spectrum antiviral compound that inhibits pyrimidine biosynthesis and establishes a type 1 interferon-independent antiviral state. Antimicrob Agents Chemother 60(8):4552-4562. https://doi.org/10.1128/AAC.00282-16

Colpitts CC, Schang LM (2014) A small molecule inhibits virion attachment to heparan sulfate- or sialic acid-containing glycans. J Virol 88(14):7806-7817. https://doi.org/10.1128/JVI.0089614

Constantinescu SN, Cernescu CD, Popescu LM (1991) Effects of protein kinase C inhibitors on viral entry and infectivity. FEBS Lett 292(1-2):31-33. https://doi.org/10.1016/0014-5793(91) 80826-o

Crutcher WA, Moschella SL (1975) Double-blind controlled crossover high-dose study of Azaribine in psoriasis. Br J Dermatol 92(2):199-205. https://doi.org/10.1111/j.1365-2133. 1975.tb03059.x 
Cruz DJ, Bonotto RM, Gomes RG, da Silva CT, Taniguchi JB, No JH et al (2013) Identification of novel compounds inhibiting Chikungunya virus-induced cell death by high throughput screening of a kinase inhibitor library. PLoS Negl Trop Dis 7(10):e2471. https://doi.org/10. 1371/journal.pntd.0002471

Das I, Basantray I, Mamidi P, Nayak TK, Pratheek BM, Chattopadhyay S, Chattopadhyay S (2014a) Heat shock protein 90 positively regulates Chikungunya virus replication by stabilizing viral non-structural protein nsP2 during infection. PLoS One. 9(6):e100531. https:// doi.org/10.1371/journal.pone.0100531

Das PK, Merits A, Lulla A (2014b) Functional cross-talk between distant domains of Chikungunya virus non-structural protein 2 is decisive for its RNA-modulating activity. J Biol Chem 289(9):5635-5653. https://doi.org/10.1074/jbc.M113.503433

Das PK, Puusepp L, Varghese FS, Utt A, Ahola T, Kananovich DG et al (2016) Design and validation of novel Chikungunya virus protease inhibitors. Antimicrob Agents Chemother 60 (12):7382-7395. https://doi.org/10.1128/AAC.01421-16

De Clercq E (2007) The design of drugs for HIV and HCV. Nat Rev Drug Discov 6(12):10011018. https://doi.org/10.1038/nrd2424

de Groot RJ, Hardy WR, Shirako Y, Strauss JH (1990) Cleavage-site preferences of Sindbis virus polyproteins containing the non-structural proteinase. Evidence for temporal regulation of polyprotein processing in vivo. EMBO J 9(8):2631-2638

Delang L, Li C, Tas A, Querat G, Albulescu IC, De Burghgraeve T et al (2016) The viral capping enzyme nsP1: a novel target for the inhibition of Chikungunya virus infection. Sci Rep 6:31819. https://doi.org/10.1038/srep31819

Delang L, Segura Guerrero N, Tas A, Querat G, Pastorino B, Froeyen M et al (2014) Mutations in the Chikungunya virus non-structural proteins cause resistance to favipiravir (T-705), a broad-spectrum antiviral. J Antimicrob Chemother 69(10):2770-2784. https://doi.org/10.1093/ jac/dku209

Delogu I, Pastorino B, Baronti C, Nougairede A, Bonnet E, de Lamballerie X (2011) In vitro antiviral activity of arbidol against Chikungunya virus and characteristics of a selected resistant mutant. Antiviral Res 90(3):99-107. https://doi.org/10.1016/j.antiviral.2011.03.182

Deneau DG, Farber EM (1975) The treatment of psoriasis with azaribine. Dermatologica 151 (3): $158-163$

Dhindwal S, Kesari P, Singh H, Kumar P, Tomar S (2017) Conformer and pharmacophore based identification of peptidomimetic inhibitors of Chikungunya virus nsP2 protease. J Biomol Struct Dyn 35(16):3522-3539. https://doi.org/10.1080/07391102.2016.1261046

Di Mola A, Peduto A, La Gatta A, Delang L, Pastorino B, Neyts J et al (2014) Structure-activity relationship study of arbidol derivatives as inhibitors of Chikungunya virus replication. Bioorg Med Chem 22(21):6014-6025. https://doi.org/10.1016/j.bmc.2014.09.013

Dryga SA, Dryga OA, Schlesinger S (1997) Identification of mutations in a sindbis virus variant able to establish persistent infection in BHK cells: the importance of a mutation in the nsP2 gene. Virology 228(1):74-83. https://doi.org/10.1006/viro.1996.8364

Dubin DT, Stollar V (1975) Methylation of sindbis virus "26S" messenger RNA. Biochem Biophys Res Commun 66(4):1373-1379. https://doi.org/10.1016/0006-291x(75)90511-2

Dubin DT, Stollar V, Hsuchen CC, Timko K, Guild GM (1977) Sindbis virus messenger RNA: the 5'-termini and methylated residues of 26 and 42 S RNA. Virology 77(2):457-470. https://doi. org/10.1016/0042-6822(77)90471-8

Ehteshami M, Tao S, Zandi K, Hsiao HM, Jiang Y, Hammond E et al (2017) Characterization of $\beta$-d-N(4)-Hydroxycytidine as a novel inhibitor of Chikungunya virus. Antimicrob Agents Chemother 61(4). https://doi.org/10.1128/aac.02395-16

Ekins S, Mestres J, Testa B (2007a) In silico pharmacology for drug discovery: applications to targets and beyond. Br J Pharmacol 152(1):21-37. https://doi.org/10.1038/sj.bjp.0707306

Ekins S, Mestres J, Testa B (2007b) In silico pharmacology for drug discovery: methods for virtual ligand screening and profiling. Br J Pharmacol 152(1):9-20. https://doi.org/10.1038/sj.bjp. 0707305 
Feibelman KM, Fuller BP, Li L, LaBarbera DV, Geiss BJ (2018) Identification of small molecule inhibitors of the Chikungunya virus nsP1 RNA capping enzyme. Antiviral Res 154:124-131. https://doi.org/10.1016/j.antiviral.2018.03.013

Ferreira AC, Reis PA, de Freitas CS, Sacramento CQ, Villas Boas Hoelz L, Bastos MM et al (2019) Beyond members of the Flaviviridae family, sofosbuvir also inhibits Chikungunya virus replication. Antimicrob Agents Chemother. 63(2). https://doi.org/10.1128/aac.01389-18

Fresno M, Jimenez A, Vazquez D (1977) Inhibition of translation in eukaryotic systems by harringtonine. Eur J Biochem/FEBS 72(2):323-330. https://doi.org/10.1111/j.1432-1033.1977. tb11256.x

Frolov I, Agapov E, Hoffman TA Jr, Pragai BM, Lippa M, Schlesinger S et al (1999) Selection of RNA replicons capable of persistent noncytopathic replication in mammalian cells. J Virol 73 (5):3854-3865

Frolov I, Garmashova N, Atasheva S, Frolova EI (2009) Random insertion mutagenesis of sindbis virus nonstructural protein 2 and selection of variants incapable of downregulating cellular transcription. J Virol 83(18):9031-9044. https://doi.org/10.1128/JVI.00850-09

Frolova EI, Gorchakov R, Pereboeva L, Atasheva S, Frolov I (2010) Functional Sindbis virus replicative complexes are formed at the plasma membrane. J Virol 84(22):11679-11695. https://doi.org/10.1128/JVI.01441-10

Fros JJ, Domeradzka NE, Baggen J, Geertsema C, Flipse J, Vlak JM et al (2012) Chikungunya virus nsP3 blocks stress granule assembly by recruitment of G3BP into cytoplasmic foci. J Virol 86(19):10873-10879. https://doi.org/10.1128/JVI.01506-12

Fros JJ, Geertsema C, Zouache K, Baggen J, Domeradzka N, van Leeuwen DM et al (2015) Mosquito Rasputin interacts with Chikungunya virus nsP3 and determines the infection rate in Aedes albopictus. Parasit Vectors 8:464. https://doi.org/10.1186/s13071-015-1070-4

Furuta Y, Gowen BB, Takahashi K, Shiraki K, Smee DF, Barnard DL (2013) Favipiravir (T-705), a novel viral RNA polymerase inhibitor. Antiviral Res 100(2):446-454. https://doi.org/10. 1016/j.antiviral.2013.09.015

Furuta Y, Komeno T, Nakamura T (2017) Favipiravir (T-705), a broad spectrum inhibitor of viral RNA polymerase. Proc Jpn Acad Ser B Phys Biol Sci 93(7):449-463. https://doi.org/10.2183/ pjab.93.027

Furuta Y, Takahashi K, Kuno-Maekawa M, Sangawa H, Uehara S, Kozaki K et al (2005) Mechanism of action of T-705 against influenza virus. Antimicrob Agents Chemother 49 (3):981-986. https://doi.org/10.1128/AAC.49.3.981-986.2005

Gao Y, Goonawardane N, Ward J, Tuplin A, Harris M (2019) Multiple roles of the non-structural protein 3 (nsP3) alphavirus unique domain (AUD) during Chikungunya virus genome replication and transcription. PLoS Pathog 15(1):e1007239. https://doi.org/10.1371/journal. ppat. 1007239

Garoff H, Sjoberg M, Cheng RH (2004) Budding of alphaviruses. Virus Res 106(2):103-116. https://doi.org/10.1016/j.virusres.2004.08.008

Gerardin P, Guernier V, Perrau J, Fianu A, Le Roux K, Grivard P et al (2008) Estimating Chikungunya prevalence in La Reunion Island outbreak by serosurveys: two methods for two critical times of the epidemic. BMC Infect Dis 8:99. https://doi.org/10.1186/1471-2334-8-99

Gigante A, Canela MD, Delang L, Priego EM, Camarasa MJ, Querat G et al (2014) Identification of $[1,2,3]$ triazolo[4,5-d]pyrimidin-7 $(6 \mathrm{H})$-ones as novel inhibitors of Chikungunya virus replication. J Med Chem 57(10):4000-4008. https://doi.org/10.1021/jm401844c

Gigante A, Gomez-SanJuan A, Delang L, Li C, Bueno O, Gamo AM et al (2017) Antiviral activity of $[1,2,3]$ triazolo[4,5-d]pyrimidin-7 $(6 \mathrm{H})$-ones against Chikungunya virus targeting the viral capping nsP1. Antiviral Res 144:216-222. https://doi.org/10.1016/j.antiviral.2017.06.003

Gopakumar H, Ramachandran S (2012) Congenital Chikungunya. J Clin Neonatol 1(3):155-156. https://doi.org/10.4103/2249-4847.101704

Gorchakov R, Frolova E, Frolov I (2005) Inhibition of transcription and translation in Sindbis virus-infected cells. J Virol 79(15):9397-9409 
Gupta DK, Kaur P, Leong ST, Tan LT, Prinsep MR, Chu JJ (2014) Anti-Chikungunya viral activities of aplysiatoxin-related compounds from the marine cyanobacterium Trichodesmium erythraeum. Mar Drugs 12(1):115-127. https://doi.org/10.3390/md12010115

Hallenberger S, Bosch V, Angliker H, Shaw E, Klenk HD, Garten W (1992) Inhibition of furin-mediated cleavage activation of HIV-1 glycoprotein gp160. Nature 360(6402):358-361. https://doi.org/10.1038/360358a0

Heidner HW, Knott TA, Johnston RE (1996) Differential processing of sindbis virus glycoprotein PE2 in cultured vertebrate and arthropod cells. J Virol 70(3):2069-2073

Heidner HW, McKnight KL, Davis NL, Johnston RE (1994) Lethality of PE2 incorporation into Sindbis virus can be suppressed by second-site mutations in E3 and E2. J Virol 68(4):26832692

Ho YJ, Wang YM, Lu JW, Wu TY, Lin LI, Kuo SC et al (2015) Suramin inhibits Chikungunya virus entry and transmission. PLoS ONE 10(7):e0133511. https://doi.org/10.1371/journal. pone. 0133511

Hoffmann HH, Kunz A, Simon VA, Palese P, Shaw ML (2011) Broad-spectrum antiviral that interferes with de novo pyrimidine biosynthesis. Proc Natl Acad Sci USA 108(14):5777-5782. https://doi.org/10.1073/pnas.1101143108

Hoornweg TE, van Duijl-Richter MKS, Ayala Nunez NV, Albulescu IC, van Hemert MJ, Smit JM (2016) Dynamics of Chikungunya virus cell entry unraveled by single-virus tracking in living cells. J Virol 90(9):4745-4756. https://doi.org/10.1128/JVI.03184-15

Jacobs SC, Taylor A, Herrero LJ, Mahalingam S, Fazakerley JK 2017 (2017) Mutation of a conserved nuclear export sequence in Chikungunya virus capsid protein disrupts host cell nuclear import. Viruses 9(10). https://doi.org/10.3390/v9100306

Jadav SS, Sinha BN, Hilgenfeld R, Jayaprakash V (2017) Computer-aided structure based drug design approaches for the discovery of new anti-CHIKV agents. Curr Comput Aided Drug Des 13(4):346-361. https://doi.org/10.2174/1573409913666170309145308

Jadav SS, Sinha BN, Hilgenfeld R, Pastorino B, de Lamballerie X, Jayaprakash V (2015) Thiazolidone derivatives as inhibitors of Chikungunya virus. Eur J Med Chem 89:172-178. https://doi.org/10.1016/j.ejmech.2014.10.042

Jhaveri K, Modi S (2015) Ganetespib: research and clinical development. Onco Targets Ther 8:1849-1858. https://doi.org/10.2147/OTT.S65804

Jones PH, Maric M, Madison MN, Maury W, Roller RJ, Okeoma CM (2013) BST-2/ tetherin-mediated restriction of Chikungunya (CHIKV) VLP budding is counteracted by CHIKV non-structural protein 1 (nsP1). Virology 438(1):37-49. https://doi.org/10.1016/j.virol. 2013.01.010

Jose J, Przybyla L, Edwards TJ, Perera R, Burgner JW 2nd, Kuhn RJ (2012) Interactions of the cytoplasmic domain of Sindbis virus E2 with nucleocapsid cores promote alphavirus budding. J Virol 86(5):2585-2599. https://doi.org/10.1128/JVI.05860-11

Jose J, Snyder JE, Kuhn RJ (2009) A structural and functional perspective of alphavirus replication and assembly. Future Microbiol 4(7):837-856. https://doi.org/10.2217/fmb.09.59

Kaihatsu K, Yamabe M, Ebara Y (2018) Antiviral mechanism of action of epigallocatechin-3-Ogallate and its fatty acid esters. Molecules 23(10). https://doi.org/10.3390/molecules23102475

Karlas A, Berre S, Couderc T, Varjak M, Braun P, Meyer M et al (2016) A human genome-wide loss-of-function screen identifies effective Chikungunya antiviral drugs. Nat Commun 7:11320. https://doi.org/10.1038/ncomms11320

Karpe YA, Aher PP, Lole KS (2011) NTPase and 5'-RNA triphosphatase activities of Chikungunya virus nsP2 protein. PLoS ONE 6(7):e22336. https://doi.org/10.1371/journal. pone. 0022336

Kaur P, Thiruchelvan M, Lee RC, Chen H, Chen KC, Ng ML et al (2013) Inhibition of Chikungunya virus replication by harringtonine, a novel antiviral that suppresses viral protein expression. Antimicrob Agents Chemother 57(1):155-167. https://doi.org/10.1128/AAC. 01467-12

Keating JA, Striker R (2012) Phosphorylation events during viral infections provide potential therapeutic targets. Rev Med Virol 22(3):166-181. https://doi.org/10.1002/rmv.722 
Khan M, Dhanwani R, Patro IK, Rao PV, Parida MM (2011) Cellular IMPDH enzyme activity is a potential target for the inhibition of Chikungunya virus replication and virus induced apoptosis in cultured mammalian cells. Antiviral Res 89(1):1-8. https://doi.org/10.1016/j.antiviral.2010. 10.009

Khan M, Santhosh SR, Tiwari M, Lakshmana Rao PV, Parida M (2010) Assessment of in vitro prophylactic and therapeutic efficacy of chloroquine against Chikungunya virus in vero cells. J Med Virol 82(5):817-824. https://doi.org/10.1002/jmv.21663

Kielian M, Chanel-Vos C, Liao M (2010) Alphavirus entry and membrane fusion. Viruses 2 (4):796-825. https://doi.org/10.3390/v2040796

Kim HY, Patkar C, Warrier R, Kuhn R, Cushman M (2005) Design, synthesis, and evaluation of dioxane-based antiviral agents targeted against the Sindbis virus capsid protein. Bioorg Med Chem Lett 15(13):3207-3211. https://doi.org/10.1016/j.bmcl.2005.05.013

Kim KH, Rumenapf T, Strauss EG, Strauss JH (2004) Regulation of Semliki Forest virus RNA replication: a model for the control of alphavirus pathogenesis in invertebrate hosts. Virology 323(1):153-163. https://doi.org/10.1016/j.virol.2004.03.009

Klimstra WB, Heidner HW, Johnston RE (1999) The furin protease cleavage recognition sequence of sindbis virus PE2 can mediate virion attachment to cell surface heparan sulfate. J Virol 73 (8):6299-6306

Langsjoen RM, Auguste AJ, Rossi SL, Roundy CM, Penate HN, Kastis M et al (2017) Host oxidative folding pathways offer novel anti-Chikungunya virus drug targets with broad spectrum potential. Antiviral Res 143:246-251. https://doi.org/10.1016/j.antiviral.2017.04.014

Lark T, Keck F, Narayanan A (2017) Interactions of alphavirus nsP3 protein with host proteins. Front Microbiol 8:2652. https://doi.org/10.3389/fmicb.2017.02652

Lebrun G, Chadda K, Reboux AH, Martinet O, Gauzere BA (2009) Guillain-Barre syndrome after Chikungunya infection. Emerg Infect Dis 15(3):495-496. https://doi.org/10.3201/eid1503. 071482

Lee CHR, Mohamed Hussain K, Chu JJH (2019) Macropinocytosis dependent entry of Chikungunya virus into human muscle cells. PLoS Negl Trop Dis 13(8):e0007610. https:// doi.org/10.1371/journal.pntd.0007610

Leyssen P, De Clercq E, Neyts J (2006) The anti-yellow fever virus activity of ribavirin is independent of error-prone replication. Mol Pharmacol 69(4):1461-1467. https://doi.org/10. 1124/mol.105.020057

Li L, Jose J, Xiang Y, Kuhn RJ, Rossmann MG (2010) Structural changes of envelope proteins during alphavirus fusion. Nature 468(7324):705-708. https://doi.org/10.1038/nature09546

Linger BR, Kunovska L, Kuhn RJ, Golden BL (2004) Sindbis virus nucleocapsid assembly: RNA folding promotes capsid protein dimerization. RNA 10(1):128-138. https://doi.org/10.1261/ rna.5127104

Lu JW, Hsieh PS, Lin CC, Hu MK, Huang SM, Wang YM et al (2017) Synergistic effects of combination treatment using EGCG and suramin against the Chikungunya virus. Biochem Biophys Res Commun 491(3):595-602. https://doi.org/10.1016/j.bbrc.2017.07.157

Lucas-Hourani M, Dauzonne D, Jorda P, Cousin G, Lupan A, Helynck O et al (2013a) Inhibition of pyrimidine biosynthesis pathway suppresses viral growth through innate immunity. PLoS Pathog 9(10):e1003678. https://doi.org/10.1371/journal.ppat.1003678

Lucas-Hourani M, Lupan A, Despres P, Thoret S, Pamlard O, Dubois J et al (2013b) A phenotypic assay to identify Chikungunya virus inhibitors targeting the nonstructural protein nsP2. J Biomol Screen 18(2):172-179. https://doi.org/10.1177/1087057112460091

Lyra PP, Campos GS, Bandeira ID, Sardi SI, Costa LF, Santos FR et al (2016) Congenital Chikungunya virus infection after an outbreak in Salvador, Bahia, Brazil. AJP Rep 6(3):e299e300. https://doi.org/10.1055/s-0036-1587323

Machkovech HM, Bloom JD, Subramaniam AR (2019) Comprehensive profiling of translation initiation in influenza virus infected cells. PLoS Pathog 15(1):e1007518. https://doi.org/10. 1371/journal.ppat. 1007518

Malet H, Coutard B, Jamal S, Dutartre H, Papageorgiou N, Neuvonen M et al (2009) The crystal structures of Chikungunya and venezuelan equine encephalitis virus nsP3 macro domains 
define a conserved adenosine binding pocket. J Virol 83(13):6534-6545. https://doi.org/10. 1128/JVI.00189-09

Manns MP, von Hahn T (2013) Novel therapies for hepatitis C - one pill fits all? Nat Rev Drug Discov 12(8):595-610. https://doi.org/10.1038/nrd4050

McPherson RL, Abraham R, Sreekumar E, Ong SE, Cheng SJ, Baxter VK et al (2017) ADP-ribosylhydrolase activity of Chikungunya virus macrodomain is critical for virus replication and virulence. Proc Natl Acad Sci USA 114(7):1666-1671. https://doi.org/10.1073/ pnas. 1621485114

Melancon P, Garoff H (1987) Processing of the Semliki Forest virus structural polyprotein: role of the capsid protease. J Virol 61(5):1301-1309

Metz SW, Pijlman GP (2016a) Function of Chikungunya virus structural proteins. In: Okeoma CM (ed) Chikungunya virus advances in biology, pathogenesis, and treatment, pp 63-74. Switzerland: Springer, Cham

Metz SW, Pijlman GP (2016b) Production of Chikungunya virus-like particles and subunit vaccines in insect cells. Methods Mol Biol 1426:297-309. https://doi.org/10.1007/978-1-49393618-2_27

Mishra P, Kumar A, Mamidi P, Kumar S, Basantray I, Saswat T et al (2016) Inhibition of Chikungunya virus replication by 1-[(2-Methylbenzimidazol-1-yl) Methyl]2-Oxo-Indolin-3-ylidene] Amino] Thiourea(MBZM-N-IBT). Sci Rep 6:20122. https://doi. org/10.1038/srep20122

Moller-Tank S, Kondratowicz AS, Davey RA, Rennert PD, Maury W (2013) Role of the phosphatidylserine receptor TIM-1 in enveloped-virus entry. J Virol 87(15):8327-8341. https://doi.org/10.1128/JVI.01025-13

Mukhopadhyay S, Zhang W, Gabler S, Chipman PR, Strauss EG, Strauss JH et al (2006) Mapping the structure and function of the E1 and E2 glycoproteins in alphaviruses. Structure 14(1):6373. https://doi.org/10.1016/j.str.2005.07.025

Nayak TK, Mamidi P, Kumar A, Singh LP, Sahoo SS, Chattopadhyay S et al (2017) Regulation of viral replication, apoptosis and pro-inflammatory responses by 17-AAG during Chikungunya virus infection in macrophages. Viruses 9(1). https://doi.org/10.3390/v9010003

Nguyen PT, Yu H, Keller PA (2014) Discovery of in silico hits targeting the nsP3 macro domain of Chikungunya virus. J Mol Model 20(5):2216. https://doi.org/10.1007/s00894-014-2216-6

Nguyen PT, Yu H, Keller PA (2015) Identification of Chikungunya virus nsP2 protease inhibitors using structure-base approaches. J Mol Graph Model 57:1-8. https://doi.org/10.1016/j.jmgm. 2015.01.001

Ooi YS, Stiles KM, Liu CY, Taylor GM, Kielian M (2013) Genome-wide RNAi screen identifies novel host proteins required for alphavirus entry. PLoS Pathog 9(12):e1003835. https://doi.org/ 10.1371/journal.ppat.1003835

Ortiz-Riano E, Ngo N, Devito S, Eggink D, Munger J, Shaw ML et al (2014) Inhibition of arenavirus by A3, a pyrimidine biosynthesis inhibitor. J Virol 88(2):878-889. https://doi.org/ 10.1128/JVI.02275-13

Ozden S, Lucas-Hourani M, Ceccaldi PE, Basak A, Valentine M, Benjannet S et al (2008) Inhibition of Chikungunya virus infection in cultured human muscle cells by furin inhibitors: impairment of the maturation of the E2 surface glycoprotein. J Biol Chem 283(32):2189921908. doi: M802444200 [pii] https://doi.org/10.1074/jbc.m802444200

Paeshuyse J, Dallmeier K, Neyts J (2011) Ribavirin for the treatment of chronic hepatitis C virus infection: a review of the proposed mechanisms of action. Curr Opin Virol 1(6):590-598. https://doi.org/10.1016/j.coviro.2011.10.030

Panas MD, Ahola T, McInerney GM (2014) The C-terminal repeat domains of nsP3 from the old world alphaviruses bind directly to G3BP. J Virol 88(10):5888-5893. https://doi.org/10.1128/ JVI.00439-14

Panas MD, Varjak M, Lulla A, Eng KE, Merits A, Karlsson Hedestam GB et al (2012) Sequestration of G3BP coupled with efficient translation inhibits stress granules in Semliki Forest virus infection. Mol Biol Cell 23(24):4701-4712. https://doi.org/10.1091/mbc.E12-080619 
Pawlotsky JM (2014) New hepatitis C virus (HCV) drugs and the hope for a cure: concepts in anti-HCV drug development. Semin Liver Dis 34(1):22-29. https://doi.org/10.1055/s-00341371007

Pietila MK, Hellstrom K, Ahola T (2017) Alphavirus polymerase and RNA replication. Virus Res 234:44-57. https://doi.org/10.1016/j.virusres.2017.01.007

Pohjala L, Utt A, Varjak M, Lulla A, Merits A, Ahola T et al (2011) Inhibitors of alphavirus entry and replication identified with a stable Chikungunya replicon cell line and virus-based assays. PLoS ONE 6(12):e28923. https://doi.org/10.1371/journal.pone.0028923

Pokorna J, Machala L, Rezacova P, Konvalinka J (2009) Current and novel inhibitors of HIV protease. Viruses 1(3):1209-1239. https://doi.org/10.3390/v1031209

Rada B, Dragun M (1977) Antiviral action and selectivity of 6-azauridine. Ann NY Acad Sci 284:410-417. https://doi.org/10.1111/j.1749-6632.1977.tb21977.x

Ramakrishnan C, Kutumbarao NHV, Suhitha S, Velmurugan D (2017) Structure-function relationship of Chikungunya nsP2 protease: a comparative study with papain. Chem Biol Drug Des 89(5):772-782. https://doi.org/10.1111/cbdd.12901

Rathore AP, Haystead T, Das PK, Merits A, Ng ML, Vasudevan SG (2014) Chikungunya virus nsP3 \& nsP4 interacts with HSP-90 to promote virus replication: HSP-90 inhibitors reduce CHIKV infection and inflammation in vivo. Antiviral Res 103:7-16. https://doi.org/10.1016/j. antiviral.2013.12.010

Rathore AP, Ng ML, Vasudevan SG (2013) Differential unfolded protein response during Chikungunya and Sindbis virus infection: CHIKV nsP4 suppresses eIF2alpha phosphorylation. Virol J 10:36. https://doi.org/10.1186/1743-422X-10-36

Raveh A, Delekta PC, Dobry CJ, Peng W, Schultz PJ, Blakely PK et al (2013) Discovery of potent broad spectrum antivirals derived from marine actinobacteria. PLoS ONE 8(12):e82318. https://doi.org/10.1371/journal.pone.0082318

Reid SP, Tritsch SR, Kota K, Chiang CY, Dong L, Kenny T et al (2015) Sphingosine kinase 2 is a Chikungunya virus host factor co-localized with the viral replication complex. Emerg Microbes Infect 4(10):e61. https://doi.org/10.1038/emi.2015.61

Rezza G, Nicoletti L, Angelini R, Romi R, Finarelli AC, Panning M et al (2007) Infection with Chikungunya virus in Italy: an outbreak in a temperate region. Lancet 370(9602):1840-1846

Ribeiro Morais G, Vicente Miranda H, Santos IC, Santos I, Outeiro TF, Paulo A (2011) Synthesis and in vitro evaluation of fluorinated styryl benzazoles as amyloid-probes. Bioorg Med Chem 19(24):7698-7710. https://doi.org/10.1016/j.bmc.2011.09.065

Roques P, Thiberville SD, Dupuis-Maguiraga L, Lum FM, Labadie K, Martinon F et al (2018) Paradoxical effect of chloroquine treatment in enhancing Chikungunya virus infection. Viruses 10(5). https://doi.org/10.3390/v10050268

Rothan HA, Bahrani H, Mohamed Z, Teoh TC, Shankar EM, Rahman NA et al (2015) A combination of doxycycline and ribavirin alleviated Chikungunya infection. PLoS ONE 10(5): e0126360. https://doi.org/10.1371/journal.pone.0126360

Rubach JK, Wasik BR, Rupp JC, Kuhn RJ, Hardy RW, Smith JL (2009) Characterization of purified sindbis virus nsP4 RNA-dependent RNA polymerase activity in vitro. Virology 384 (1):201-208. https://doi.org/10.1016/j.virol.2008.10.030

Rupp JC, Sokoloski KJ, Gebhart NN, Hardy RW (2015) Alphavirus RNA synthesis and non-structural protein functions. J Gen Virol 96(9):2483-2500. https://doi.org/10.1099/jgv.0. 000249

Sahoo B, Chowdary TK (2019) Conformational changes in Chikungunya virus E2 protein upon heparan sulfate receptor binding explain mechanism of E2-E1 dissociation during viral entry. Biosci Rep 39(6). https://doi.org/10.1042/bsr20191077

Salonen A, Vasiljeva L, Merits A, Magden J, Jokitalo E, Kaariainen L (2003) Properly folded nonstructural polyprotein directs the Semliki Forest virus replication complex to the endosomal compartment. J Virol 77(3):1691-1702. https://doi.org/10.1128/jvi.77.3.1691-1702.2003

Savarino A, Boelaert JR, Cassone A, Majori G, Cauda R (2003) Effects of chloroquine on viral infections: an old drug against today's diseases? Lancet Infect Dis 3(11):722-727 
Scholte FE, Tas A, Martina BE, Cordioli P, Narayanan K, Makino S et al (2013) Characterization of synthetic Chikungunya viruses based on the consensus sequence of recent E1-226V isolates. PLoS ONE 8(8):e71047. https://doi.org/10.1371/journal.pone.0071047

Schuffenecker I, Iteman I, Michault A, Murri S, Frangeul L, Vaney MC et al (2006) Genome microevolution of Chikungunya viruses causing the Indian Ocean outbreak. PLoS Med 3(7): e263. https://doi.org/10.1371/journal.pmed.0030263

Seyedi SS, Shukri M, Hassandarvish P, Oo A, Shankar EM, Abubakar S et al (2016) Computational approach towards exploring potential anti-Chikungunya activity of selected flavonoids. Scientific reports 6:24027. https://doi.org/10.1038/srep24027

Sharma R, Fatma B, Saha A, Bajpai S, Sistla S, Dash PK et al (2016) Inhibition of Chikungunya virus by picolinate that targets viral capsid protein. Virology 498:265-276. https://doi.org/10. 1016/j.virol.2016.08.029

Sharma R, Kesari P, Kumar P, Tomar S (2018) Structure-function insights into Chikungunya virus capsid protein: small molecules targeting capsid hydrophobic pocket. Virology 515:223-234 . https://doi.org/10.1016/j.virol.2017.12.020

Shirako Y, Strauss JH (1994) Regulation of sindbis virus RNA replication: uncleaved P123 and nsP4 function in minus-strand RNA synthesis, whereas cleaved products from P123 are required for efficient plus-strand RNA synthesis. J Virol 68(3):1874-1885

Silva LA, Khomandiak S, Ashbrook AW, Weller R, Heise MT, Morrison TE et al (2014) A single-amino-acid polymorphism in Chikungunya virus E2 glycoprotein influences glycosaminoglycan utilization. J Virol 88(5):2385-2397. https://doi.org/10.1128/JVI.03116-13

Simmons DT, Strauss JH (1972) Replication of Sindbis virus. I. Relative size and genetic content of $26 \mathrm{~s}$ and $49 \mathrm{~s}$ RNA. J Mol Biol 71(3):599-613

Simon F, Javelle E, Cabie A, Bouquillard E, Troisgros O, Gentile G et al (2015) French guidelines for the management of Chikungunya (acute and persistent presentations). November 2014. Med Mal Infect 45(7):243-263. https://doi.org/10.1016/j.medmal.2015.05.007

Singh H, Mudgal R, Narwal M, Kaur R, Singh VA, Malik A et al (2018) Chikungunya virus inhibition by peptidomimetic inhibitors targeting virus-specific cysteine protease. Biochimie 149:51-61. https://doi.org/10.1016/j.biochi.2018.04.004

Sissoko D, Malvy D, Ezzedine K, Renault P, Moscetti F, Ledrans M et al (2009) Post-epidemic Chikungunya disease on reunion island: course of rheumatic manifestations and associated factors over a 15-month period. PLoS Negl Trop Dis 3(3):e389. https://doi.org/10.1371/ journal.pntd.0000389

Smee DF, Hurst BL, Day CW (2012) D282, a non-nucleoside inhibitor of influenza virus infection that interferes with de novo pyrimidine biosynthesis. Antivir Chem Chemother 22(6):263-272. https://doi.org/10.3851/IMP2105

Sokoloski KJ, Nease LM, May NA, Gebhart NN, Jones CE, Morrison TE et al (2017) Identification of interactions between sindbis virus capsid protein and cytoplasmic vRNA as novel virulence determinants. PLoS Pathog 13(6):e1006473. https://doi.org/10.1371/journal. ppat. 1006473

Solignat M, Gay B, Higgs S, Briant L, Devaux C (2009) Replication cycle of Chikungunya: a re-emerging arbovirus. Virology 393(2):183-197. https://doi.org/10.1016/j.virol.2009.07.024

Spuul P, Balistreri G, Kaariainen L, Ahola T (2010) Phosphatidylinositol 3-kinase-, actin-, and microtubule-dependent transport of Semliki Forest virus replication complexes from the plasma membrane to modified lysosomes. J Virol 84(15):7543-7557. https://doi.org/10.1128/ JVI.00477-10

Spuul P, Salonen A, Merits A, Jokitalo E, Kaariainen L, Ahola T (2007) Role of the amphipathic peptide of Semliki Forest virus replicase protein nsP1 in membrane association and virus replication. J Virol 81(2):872-883. https://doi.org/10.1128/JVI.01785-06

Stangherlin LM, de Paula FN, Icimoto MY, Ruiz LGP, Nogueira ML, Braz ASK et al (2017) Positively selected sites at HCMV gB furin processing region and their effects in cleavage efficiency. Frontiers in microbiology 8:934. https://doi.org/10.3389/fmicb.2017.00934

Staveness D, Abdelnabi R, Near KE, Nakagawa Y, Neyts J, Delang L et al (2016) Inhibition of Chikungunya virus-induced cell death by salicylate-derived bryostatin analogues provides 
additional evidence for a PKC-independent pathway. J Nat Prod 79(4):680-684. https://doi. org/10.1021/acs.jnatprod.5b01017

Strauss EG, Rice CM, Strauss JH (1984) Complete nucleotide sequence of the genomic RNA of sindbis virus. Virology 133(1):92-110. https://doi.org/10.1016/0042-6822(84)90428-8

Strauss JH, Strauss EG (1994) The alphaviruses: gene expression, replication, and evolution. Microbiol Rev 58(3):491-562

Subudhi BB, Chattopadhyay S, Mishra P, Kumar A (2018) Current strategies for inhibition of Chikungunya infection. Viruses 10(5). https://doi.org/10.3390/v10050235

Tamm K, Merits A, Sarand I (2008) Mutations in the nuclear localization signal of nsP2 influencing RNA synthesis, protein expression and cytotoxicity of Semliki Forest virus. J Gen Virol 89(Pt 3):676-686. https://doi.org/10.1099/vir.0.83320-0

Taylor A, Liu X, Zaid A, Goh LY, Hobson-Peters J, Hall RA et al (2017) Mutation of the Nterminal region of Chikungunya virus capsid protein: implications for vaccine design. mBio 8 (1). https://doi.org/10.1128/mbio.01970-16

Thaa B, Biasiotto R, Eng K, Neuvonen M, Gotte B, Rheinemann L et al (2015) Differential phosphatidylinositol-3-kinase-Akt-mTOR activation by Semliki Forest and Chikungunya viruses is dependent on nsP3 and connected to replication complex internalization. J Virol 89 (22):11420-11437. https://doi.org/10.1128/JVI.01579-15

Thomas S, Rai J, John L, Gunther S, Drosten C, Putzer BM et al (2010) Functional dissection of the alphavirus capsid protease: sequence requirements for activity. Virol J 7:327. https://doi. org/10.1186/1743-422X-7-327

Thomas S, Rai J, John L, Schaefer S, Putzer BM, Herchenroder O (2013) Chikungunya virus capsid protein contains nuclear import and export signals. Virol J 10:269. https://doi.org/10. 1186/1743-422X-10-269

Tomar S, Hardy RW, Smith JL, Kuhn RJ (2006) Catalytic core of alphavirus nonstructural protein nsP4 possesses terminal adenylyltransferase activity. J Virol 80(20):9962-9969. https://doi. org/10.1128/JVI.01067-06

Tsetsarkin KA, Vanlandingham DL, McGee CE, Higgs S (2007) A single mutation in Chikungunya virus affects vector specificity and epidemic potential. PLoS Pathog 3(12):e201

Turner TL, Kopp BT, Paul G, Landgrave LC, Hayes D Jr, Thompson R (2014) Respiratory syncytial virus: current and emerging treatment options. Clinicoecon Outcomes Res 6:217225. https://doi.org/10.2147/CEOR.S60710

Uchime O, Fields W, Kielian M (2013) The role of E3 in pH protection during alphavirus assembly and exit. J Virol 87(18):10255-10262. https://doi.org/10.1128/JVI.01507-13

Urakova N, Kuznetsova V, Crossman DK, Sokratian A, Guthrie DB, Kolykhalov AA et al (2018) $\beta$-D-N (4)-hydroxycytidine is a potent anti-alphavirus compound that induces a high level of mutations in the viral genome. J Virol 92(3). https://doi.org/10.1128/jvi.01965-17

Utt A, Quirin T, Saul S, Hellstrom K, Ahola T, Merits A (2016) Versatile trans-replication systems for Chikungunya virus allow functional analysis and tagging of every replicase protein. PLoS ONE 11(3):e0151616. https://doi.org/10.1371/journal.pone.0151616

van der Heijden MW, Bol JF (2002) Composition of alphavirus-like replication complexes: involvement of virus and host encoded proteins. Arch Virol 147(5):875-898. https://doi.org/ 10.1007/s00705-001-0773-3

van Duijl-Richter MK, Hoornweg TE, Rodenhuis-Zybert IA, Smit JM (2015) Early events in Chikungunya virus infection-from virus cell binding to membrane fusion. Viruses 7(7):36473674. https://doi.org/10.3390/v7072792

Vasiljeva L, Merits A, Golubtsov A, Sizemskaja V, Kaariainen L, Ahola T (2003) Regulation of the sequential processing of Semliki Forest virus replicase polyprotein. J Biol Chem 278 (43):41636-41645. https://doi.org/10.1074/jbc.M307481200

Venturi G, Di Luca M, Fortuna C, Remoli ME, Riccardo F, Severini F et al (2017) Detection of a Chikungunya outbreak in Central Italy, August-September 2017. Euro Surveill 22(39). https:// doi.org/10.2807/1560-7917.es.2017.22.39.17-00646 
Voss JE, Vaney MC, Duquerroy S, Vonrhein C, Girard-Blanc C, Crublet E et al (2010) Glycoprotein organization of Chikungunya virus particles revealed by X-ray crystallography. Nature 468(7324):709-712. https://doi.org/10.1038/nature09555

Wada Y, Orba Y, Sasaki M, Kobayashi S, Carr MJ, Nobori H et al (2017) Discovery of a novel antiviral agent targeting the nonstructural protein 4 (nsP4) of Chikungunya virus. Virology 505:102-112. https://doi.org/10.1016/j.virol.2017.02.014

Wang QY, Bushell S, Qing M, Xu HY, Bonavia A, Nunes S et al (2011) Inhibition of dengue virus through suppression of host pyrimidine biosynthesis. J Virol 85(13):6548-6556. https://doi. org/10.1128/JVI.02510-10

Weaver SC, Lecuit M (2015) Chikungunya virus and the global spread of a mosquito-borne disease. N Engl J Med 372(13):1231-1239. https://doi.org/10.1056/NEJMra1406035

Weber C, Berberich E, von Rhein C, Henss L, Hildt E, Schnierle BS (2017) Identification of functional determinants in the Chikungunya virus E2 protein. PLoS Negl Trop Dis 11(1): e0005318. https://doi.org/10.1371/journal.pntd.0005318

Weber C, Sliva K, von Rhein C, Kummerer BM, Schnierle BS (2015) The green tea catechin, epigallocatechin gallate inhibits Chikungunya virus infection. Antiviral Res 113:1-3. https:// doi.org/10.1016/j.antiviral.2014.11.001

Weiss B, Geigenmuller-Gnirke U, Schlesinger S (1994) Interactions between sindbis virus RNAs and a 68 amino acid derivative of the viral capsid protein further defines the capsid binding site. Nucleic Acids Res 22(5):780-786. https://doi.org/10.1093/nar/22.5.780

Weston JH, Graham DA, Branson E, Rowley HM, Walker IW, Jewhurst VA et al (2005) Nucleotide sequence variation in salmonid alphaviruses from outbreaks of salmon pancreas disease and sleeping disease. Dis Aquat Organ 66(2):105-111. https://doi.org/10.3354/ dao066105

Wichit S, Hamel R, Bernard E, Talignani L, Diop F, Ferraris P et al (2017) Imipramine inhibits Chikungunya virus replication in human skin fibroblasts through interference with intracellular cholesterol trafficking. Sci Rep 7(1):3145. https://doi.org/10.1038/s41598-017-03316-5

Wintachai P, Thuaud F, Basmadjian C, Roytrakul S, Ubol S, Desaubry L et al (2015) Assessment of flavaglines as potential Chikungunya virus entry inhibitors. Microbiol Immunol 59(3):129_ 141. https://doi.org/10.1111/1348-0421.12230

Wintachai P, Wikan N, Kuadkitkan A, Jaimipuk T, Ubol S, Pulmanausahakul R et al (2012) Identification of prohibitin as a Chikungunya virus receptor protein. J Med Virol 84(11):17571770. https://doi.org/10.1002/jmv.23403

Wong KZ, Chu JJH (2018) The interplay of viral and host factors in Chikungunya virus infection: targets for antiviral strategies. Viruses 10(6). https://doi.org/10.3390/v10060294

Yang S, Fink D, Hulse A, Pratt RD (2017) Regulatory considerations in development of vaccines to prevent disease caused by Chikungunya virus. Vaccine 35(37):4851-4858. https://doi.org/ 10.1016/j.vaccine.2017.07.065

Zhang R, Kim AS, Fox JM, Nair S, Basore K, Klimstra WB et al (2018) Mxra8 is a receptor for multiple arthritogenic alphaviruses. Nature 557(7706):570-574. https://doi.org/10.1038/ s41586-018-0121-3 